\title{
SOME BEARING CAPACITY CHARACTERISTICS OF A STRUCTURED NATURALLY DEPOSITED CLAY SOIL
}

\author{
Toshiniro Noda ${ }^{\text {i)}}$, Akira Asaoka ${ }^{\text {ii) }}$ and Shotaro Yamadiii)
}

\begin{abstract}
An investigation was conducted into the bearing capacity characteristics of a structured naturally deposited clay soil by means of a soil-water coupled finite deformation analysis based on unconventional elasto-plastic mechanics. The constitutive equation of the soil skeleton was expressed using the Super/subloading Yield Surface Cam-clay model (SYS Cam-clay model), an elasto-plastic constitutive equation model proposed by the authors to describe the mechanisms (structure, overconsolidation and anisotropy) at work in the skeleton structure. To allow a theoretical consideration of a typical bearing capacity problem, a case was assumed in which vertical displacement was applied through a rigid foundation possessing friction. The main conclusions of the study were:

(1) In a highly structured soil, a peak appears in the load-settlement relation, accompanied by a considerable localization of strain and a clearly visible slip line. In a soil of high initial anisotropy, the area of failure is more confined and the peak load is smaller than in an initially isotropic soil.

(2) In the case of a highly structured soil possessing an initial imperfection, even if this is very slight, a sensitive response occurs, leading to an asymmetrical deformation mode. At the same time, the load-settlement curve "bifurcates" from the path the same soil exhibits when it is deformed symmetrically, so as to display a larger decrease in load.

(3) If loading is relaxed from a rapid rate ( $\fallingdotseq$ completely undrained), at which virtually no migration of pore water can occur in the soil, to a rate that is slower, the peak load will gradually increase with the partial draining effect. If the rate of loading is reduced still further, a point will eventually be reached where no drop in load is observed and it becomes impossible to distinguish clear boundaries for the area of failure. Depending on the rate of loading, it may be possible to see the clear appearance of a compaction band, caused by soil structure decay in the area of strain localization.

These findings aim to show that the inclusion of a concept of soil skeleton structure in an analysis of this sort is not only a very natural step to take, but also an advance of the greatest importance.
\end{abstract}

Key words: bearing capacity, (finite deformation theory), (naturally deposited clay soil), (soil skeleton structure), (soil-water coupled analysis), (SYS Cam-clay model) (IGC: E3)

\section{INTRODUCTION}

Stability problems in naturally deposited clay soils, such as those containing soft clay, are generally approached with the aid of limit bearing capacity methods such as $\phi_{\mathrm{u}}=0$ circular slip analysis or soil-water coupled (Asaoka et al., 1986, 1987) rigid plastic finite element analysis (Tamura and Ohtsuka, 1984). Using the latter method, it is possible, after first calculating the void ratio distributions in a soil through an elasto-plastic consolidation deformation analysis under partially drained conditions, to project them into the rigid plastic analysis so as to obtain the bearing capacity during soil consolidation ("partially drained bearing capacity analysis" (Asaoka and Ohtsuka, 1987; Asaoka et al., 1995b)). Numerous elasto-plastic analyses have been performed, however, with the aim of treating the problems of deformation and failure as one continuum. When arguing about failure by means of a method of this kind that does not draw a division between deformation and failure, it becomes extremely important to take account of the effects of changes in geometrical shape and to include a view of bifurcation. For example, working from this kind of view in a field of solid mechanics involving general elastoplastic materials, Ikeda et al. (2003), along with a concise review of previous research, present examples of diffuse mode bifurcation analysis in a footing foundation, but using a single-phase, not a soil-water coupled system approach. But if the intention is to cover the whole continuum of change in the soil, from deformation right

i) Associate Professor, Department of Civil Engineering, Nagoya University, Japan (noda@civil.nagoya-u.ac.jp).

ii) Professor, ditto.

iii) Research Associate, Department of Civil Engineering, Fukuoka University, Japan.

The manuscript for this paper was received for review on December 9, 2005; approved on October 2, 2006.

Written discussions on this paper should be submitted before November 1, 2007 to the Japanese Geotechnical Society, 4-38-2, Sengoku, Bunkyo-ku, Tokyo 112-0011, Japan. Upon request the closing date may be extended one month. 


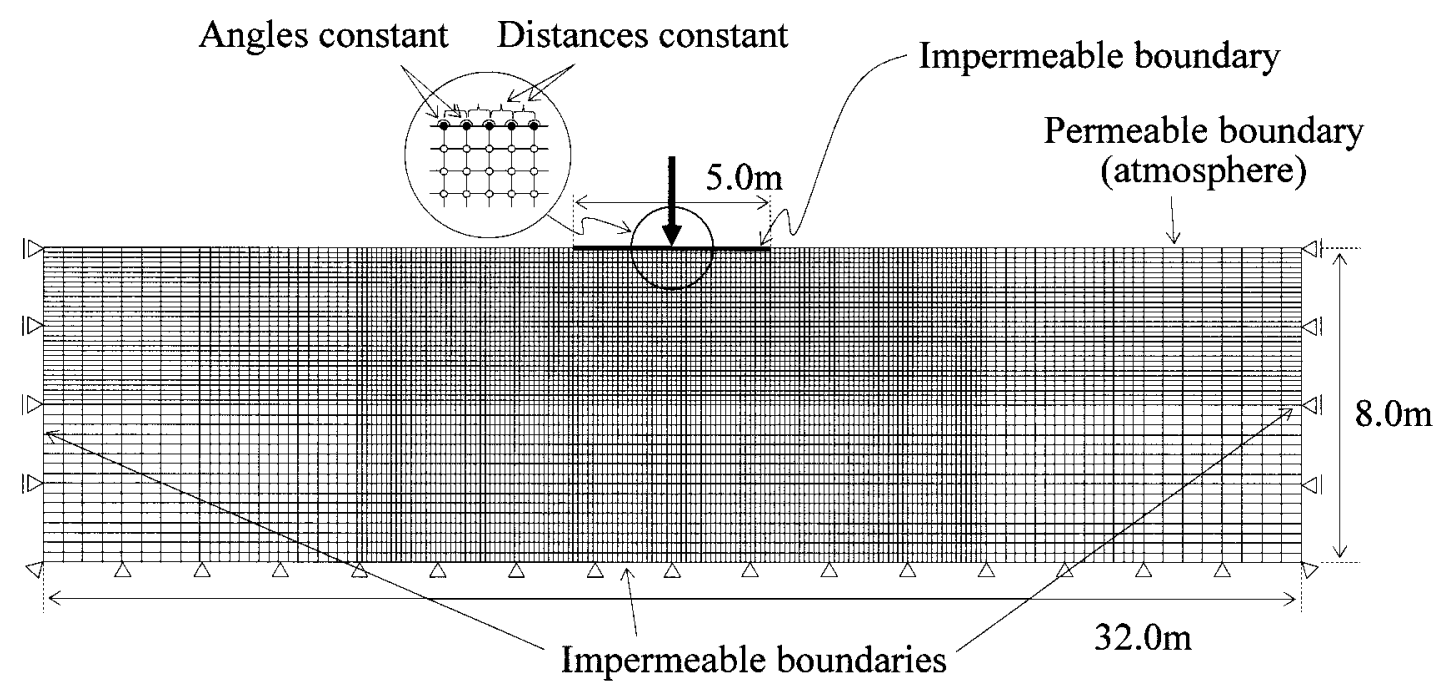

Fig. 1. Finite element mesh and boundary conditions

through to failure, then it is indispensable, in addition to the other aspects, to treat the material as a two-phased system of water and soil (Yatomi et al., 1989b; Asaoka et al., 1994). While Yatomi et al. (1989b), in their exploratory finite element analysis, considered only cases under perfectly undrained conditions involving no pore water migration, and although their study is not without errors in the calculation of the undrained effective stress path, they do certainly make use of a non-coaxial Camclay model in their constitutive soil equation (Yatomi et al., 1989a) to discuss the formation of shear bands in a punching problem. The present authors, for their part, have shown (Noda et al., 2000) how it can be made possible for consolidation and bearing capacity problems to be treated together in the single theoretical framework, which yields bearing capacity under partially drained conditions with occurrence of pore water migration. The self-weight of the material is also an important factor that will necessarily need to be reckoned with in problems concerning soils. Self-weight is not allowed for in any of the analyses mentioned above (Yatomi et al., 1989b; Ikeda et al., 2003; Noda et al., 2000), but in the present paper an attempt has been made to take account of it in a bearing capacity problem, in order to account for the spatial variation in "strength" in the depth direction due to the self-weight of the soil.

It is often noted that naturally deposited clay exists in a structurally developed state with regard to its soil skeleton, and possesses characteristic mechanical properties which a laboratory reconstituted clay cannot have. As a soil skeleton constitutive equation capable of describing the working of the skeleton structure, the authors have proposed a super/subloading yield surface modified Cam-clay model, or SYS Cam-clay model for short (Asaoka et al., 1998a, 2000, 2002). This SYS Cam-clay model is a model which takes structure, overconsolidation and anisotropy as factors determining the mode of a soil's skeleton structure and seeks to realize their working in the Cam-clay model which represents the elasto-plastic behavior of normally consolidated remolded clay. As regards anisotropy and its development or loss, in addition to the modified stress ratio $\eta^{*}$ (Sekiguchi and Ohta, 1977), the effect of which is to rotate the plastic potential surface, a rotational hardening rule (Hashiguchi and Chen, 1998) is also introduced (for details of the model, see APPENDIX A).

The present paper, dealing with a bearing capacity problem in a naturally deposited clay soil, will employ a soil-water coupled finite deformation analysis making use of the SYS Cam-clay model to show, for example, the effects exerted on bearing capacity by the soil skeleton structure on the one hand and the soil-water coupling on the other. It will be shown, in this case, that when the bearing capacity problem is solved through the natural operation of the working of the soil skeleton structure in the constitutive equation, a clear peak appears in the load magnitude-settlement relation, and at the same time there is also a remarkable localization of strain, that leads to the appearance of a sharp slip line.

\section{ANALYSIS CONDITIONS}

\section{Finite Element Mesh and Boundary Conditions}

The calculation is performed under 2-dimensional plane strain conditions. The finite element mesh and boundary conditions are as shown in Fig. 1. In order to be able to think of this as a typical bearing capacity problem, a case is assumed in which a vertical displacement is exerted on a rigid foundation possessing friction. In the representation of the foundation, line shape restrictions (invariable length, invariable angles) are imposed between adjacent nodes (Asaoka et al., 1998b), while allowance is made for an asymmetrical deformation mode permitting the foundation to tilt sideways. Concerning the hydraulic boundary conditions, the bottom and two lateral boundaries of the clay soil, as well as the ground surface on which the foundation is located, are assumed to be impermeable, while the other ground 
Table 1. Material constants in the foundation

\begin{tabular}{lc}
\multicolumn{1}{c}{ Elasto-plastic parameters } \\
\hline \multicolumn{1}{c}{ Evolution rule parameters } & 0.23 \\
Compression index $\tilde{\lambda}$ & 0.01 \\
Critical state constant $\mathrm{M}$ & 1.15 \\
Specific volume at $q=0$ and $p^{\prime}=98.1 \mathrm{kPa}$ on NCL N & 2.75 \\
Poisson's ratio $v$ & 0.1 \\
\hline \multicolumn{1}{c}{ Evolion } & \\
\hline Degradation index of structure $a(b=c=1.0)$ & 0.2 \\
Degradation index of overconsolidation $m$ & 5.0 \\
Evolution index of rotational hardening $b_{r}$ & 0.001 \\
Limit of rotational hardening $m_{b}$ & 1.0 \\
\hline Permeability $k(\mathrm{~cm} / \mathrm{sec})$ & $2.8 \times 10^{-7}$ \\
\hline Density of soil particles $\rho_{\mathrm{s}}\left(\mathrm{t} / \mathrm{m}^{3}\right)$ & 2.75 \\
\hline
\end{tabular}

surfaces are permeable (open to the atmosphere). The vertical displacement is applied to the foundation's central node at a rapid rate of $1.0 \times 10^{-3} \mathrm{~cm} / \mathrm{sec}$ so as to allow almost no migration of pore water within the soil. In the latter part of the study there will be some discussion of the effect of varying this loading rate. The difference in rates is set in steps of $2.5 \times 10^{-3} \mathrm{~cm} / \mathrm{step}$.

\section{Material Constants and Initial Conditions in the Soil}

Table 1 shows the material constants. The parameters of the evolution rule are fixed so as to capture the typical elasto-plastic behavior of clay (rapid loss of overconsolidation in comparison with the rate of structural decay, slow development of anisotropy) (Asaoka et al., 2002). The initial distribution of void ratios, overconsolidation ratios, etc. in the soil is then assigned in the following two stages.

Stage I First, the constitutive equation is used to obtain theoretical values for a horizontally homogeneous soil subjected to a surcharge loading of $98.1 \mathrm{kPa}$ under 1-dimensional conditions.

Stage II The surcharge loading is then removed from the ground surface, and the consolidation state is calculated until the soil returns to a steady state.

The bearing capacity is calculated for this overconsolidated soil without the surcharge load. As the actual numerical values for the initial state of the soil (before removal of the surcharge load) partly vary from one calculation to another, they will be separately stated below before each set of results. There are two major respects in which the treatment here is different from that applied to bearing capacity problems in the elasto-plastics of metals. First, the soil's own weight is taken into account in the equilibrium of forces; and second, the resultant increase in strength (non-homogeneity) in the direction of increasing depth is also reckoned in.

There are two things to point out concerning the initial characteristics of the soil as given by way of the two stages introduced above.

First, at stage I, assuming that the index of structural development $1 / R_{0}^{*}$, the overconsolidation ratio $1 / R_{0}$, the index of anisotropic development $\zeta_{0}$ and the effective stress ratio $\eta_{0}$ all stay at constant values in the depth direction, the result will be the formation of a clay soil that is homogeneously composed in the horizontal direction, the state of which will depend on the size of the surcharge load $\delta$ and the self-weight of the clay. At the same time, effective stress $\boldsymbol{T}_{0}^{\prime}$ and the rotational hardening variable $\boldsymbol{\beta}_{0}$, which is an expression of anisotropy, will be in a state of axial symmetry around a vertical axis. The means of formulating the state of this initial soil are set out in detail in APPENDIX B, but as a preliminary it is important to grasp the following.

Specific volume $\mathrm{v}_{0}$ is related to the initial mean effective stress on the subloading yield surface $p_{0}^{\prime}$, and to $\eta_{0}^{*}, R_{0}^{*}$ and $R_{0}$, by the following equation (Noda et al., 2005).

$$
\mathrm{v}_{0}=\mathrm{N}-\tilde{\lambda} \ln p_{0}^{\prime}-(\tilde{\lambda}-\tilde{\kappa}) \ln \frac{R_{0}^{*}}{R_{0}} \frac{\mathrm{M}^{2}+\eta_{0}^{* 2}}{\mathrm{M}^{2}}
$$

Here, $\tilde{\lambda}$ is the compression index, $\tilde{\kappa}$ is the swelling index, $\mathrm{M}$ is the critical state constant and $\mathrm{N}$ is the specific volume of normally consolidated remolded clay under conditions of $q=0, p^{\prime}=98.1 \mathrm{kPa}$. Where the effective stress $\boldsymbol{T}_{0}^{\prime}$ and the rotational hardening variable $\boldsymbol{\beta}_{0}$ are in a state of axi-symmetry, the relation $\eta_{0}^{*}=\left(\eta_{0} \mp \zeta_{0}\right)^{2}$ will additionally apply.

Given that one of the objectives in this study is to demonstrate the effect that the degree of development in the skeleton structure has on the bearing capacity characteristics of the soil, a straightforward way of achieving that might seem to be, for example, by carrying out comparisons at varying degrees of structural development, while holding all the other conditions uniform. However, a glance at Eq. (1) shows that for the five initial quantities of specific volume $\mathrm{v}_{0}$, stress state $\left(p_{0}^{\prime}, \eta_{0}\right)$, structure $R_{0}^{*}$, overconsolidation $R_{0}$ and anisotropy $\zeta_{0}$, if four values are specified the fifth will be automatically determined. This means that it is not possible for all five initial values to be specified freely. For instance, if we set values for $R_{0}, R_{0}^{*}, \zeta_{0}$ and $\eta_{0}$, the remaining value for specific volume $\mathrm{v}_{0}\left(=1+\mathrm{e}_{0}\right)$ will arise from the calculation ( $p_{0}^{\prime}$ being decided by the ground surface load and the self-weight of the soil). Hence, every time we set out to compare effects arising from differences in the degree of structural development we will also find an additional difference arising in the void ratio $\mathrm{e}_{0}$. Consequently, when some effect such as an increase or decrease in the bearing load appears in the calculation results, we need to be extremely cautious in ascertaining which of the factors it depends upon.

There is also a point to be noted regarding the effect arising in stage II. The purpose of performing this removing operation is to be able to induce overconsolidation in the soil while at the same time considering the case of the same soil without surcharge load. But looking at the various depth-dependent distributions of soil conditions (Figs. 2, 9, 12, 15 below) following the removal of the surcharge load and the completion of consolidation, that is, immediately prior to reloading, we notice that the 


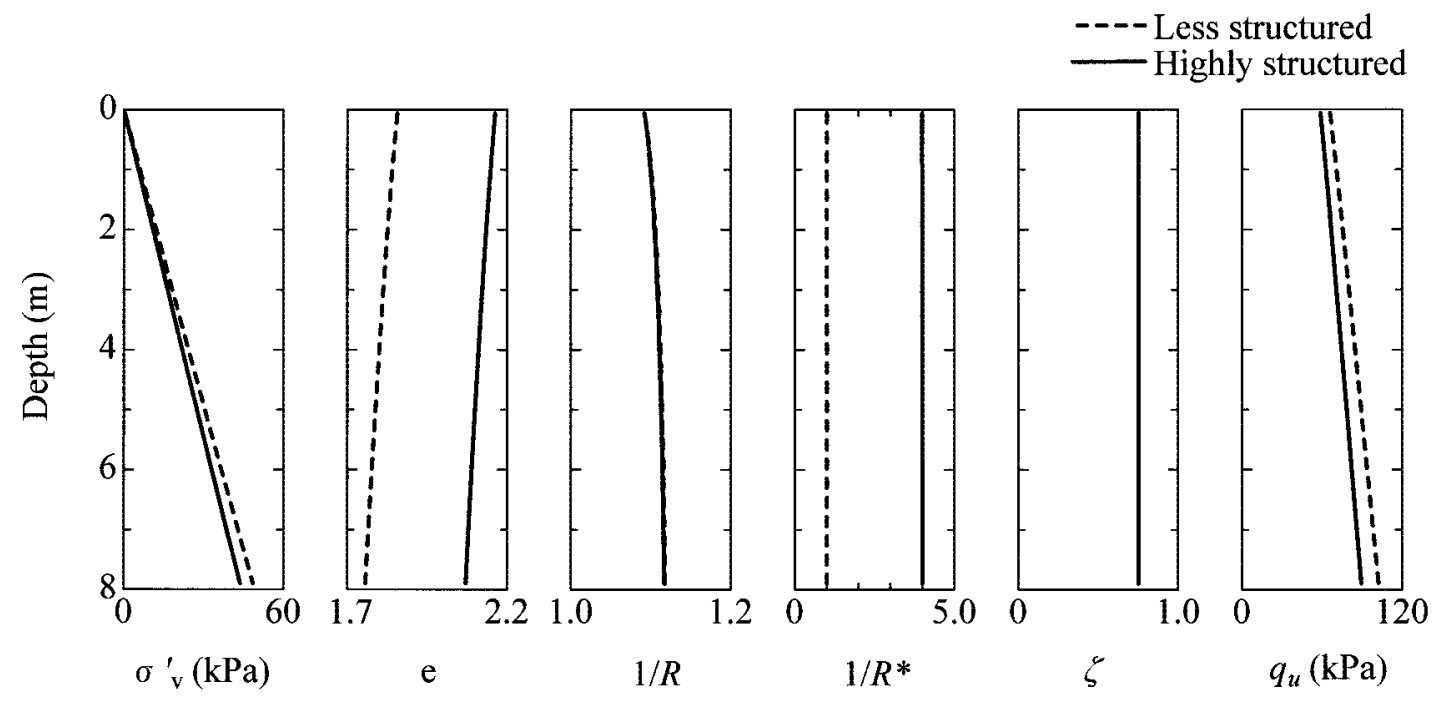

Fig. 2. Depth distributions just prior to loading (soils differing in degree of structure)

overconsolidation ratio in the elasto-plastic mechanical sense, $1 / R$, decreases in size the nearer it is to the ground surface. One would think that after the removal of the surcharge load the overconsolidation rather ought to increase with nearness to the surface, where the overburden pressure is lighter. Yet this does not necessarily seem to be so. The reason for this is that the removal of the surcharge load leads not only to elastic, but also to plastic deformation, in other words, to 'loading' in terms of elasto-plastic mechanics (Noda et al., 2005). Thus, while the process of removing the load from the ground surface may not always result in an overconsolidation of the soil, the opposite unloading effect induced in the initial states of the individual elements means that the effect appearing in the analysis results will be the equivalent of what one would expect from a soil overconsolidated from the start. Furthermore, since this effect grows greater with closer proximity to the ground surface where the overburden pressure is less, removing the surcharge load effectively causes the calculation to come up with increasing overconsolidation the nearer to the surface are the soil levels it has to deal with.

\section{EFFECTS OF THE SOIL SKELETON STRUCTURE AND ITS WORKING ON BEARING CAPACITY CHARACTERISTICS}

\section{Effects of Structure}

In order to demonstrate the effects introduced into bearing capacity problems by initial differences of degree in soil structure, two different types of soil are adopted for investigation, a remolded clay (less structured) and a clay developed in its structure (highly structured). Table 2 gives the initial conditions of these soils prior to the removal of the surcharge load, and Fig. 2 shows the depth-dependent distributions following removal and consolidation, i.e., just prior to the subsequent loading. (The values for undrained shearing "strength," $q_{u}$, in Fig. 2 represent numerically simulated unconfined
Table 2. Initial conditions in the soils (soils differing in degree of structure)

\begin{tabular}{lcc}
\hline & $\begin{array}{c}\text { Less } \\
\text { structured }\end{array}$ & $\begin{array}{c}\text { Highly } \\
\text { structured }\end{array}$ \\
\hline Degree of structure $1 / R_{0}^{*}$ & 1.0 & 4.0 \\
Overconsolidation ratio $1 / R_{0}$ & 1.0 & 1.0 \\
Degree of anisotropy $\zeta_{0}=\sqrt{3 / 2 \beta_{0} \cdot \beta_{0}}$ & 0.75 & 0.75 \\
Lateral pressure coefficient $k_{0}=\sigma_{h 0}^{\prime} / \sigma_{v 0}^{\prime}$ & 0.50 & 0.50 \\
\hline
\end{tabular}

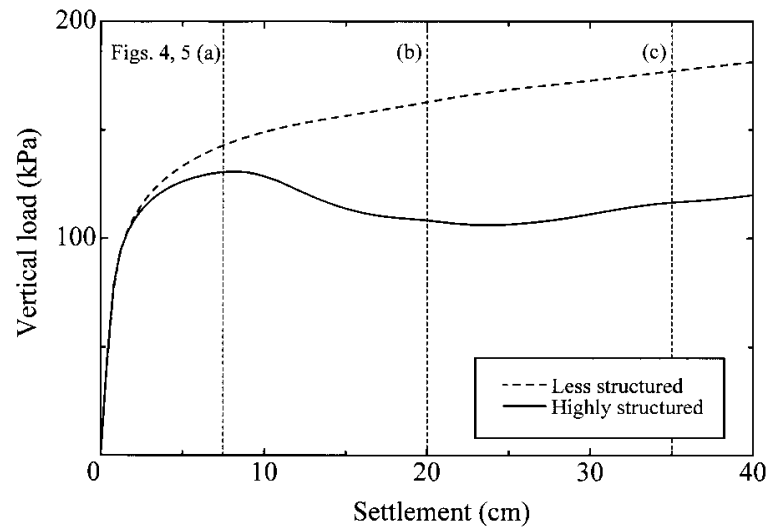

Fig. 3. Relation between load and settlement (effect of structure)

compression strengths obtained for clay soils in ideally sampled states (Noda et al., 2005).) It can be confirmed from Fig. 2 that the two clays differ considerably in their degrees of structure, $1 / R^{*}$, and, consequentially, that the values for void ratios are greater in the more structured soil.

The relation between load size and settlement can be seen in Fig. 3, and the shear strain distributions are shown in Figs. 4 and 5 (the dotted lines in Fig. 3 and the lettering in Figs. 4, 5(a) etc. show which point of time the contours in Figs. 4 and 5 correspond to. The dotted lines and lettering in Figs. 10, 13, 17, 19, 22 and 29 have a similar meaning). In the case of the remolded soil, the 


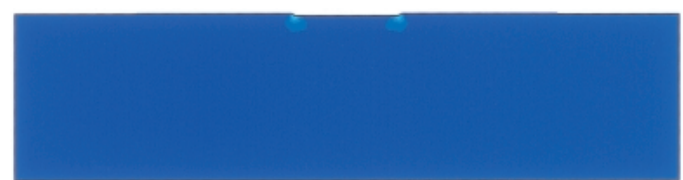

(a) Settlement $7.5 \mathrm{~cm}$

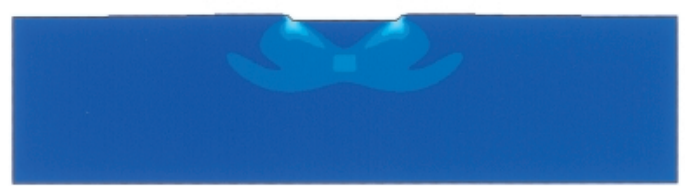

(b) Settlement $20 \mathrm{~cm}$

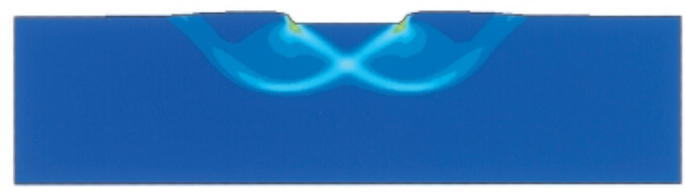

(c) Settlement $35 \mathrm{~cm}$

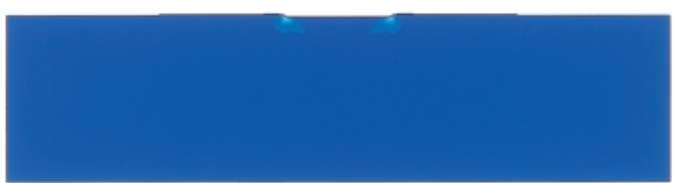

(a) Settlement $7.5 \mathrm{~cm}$

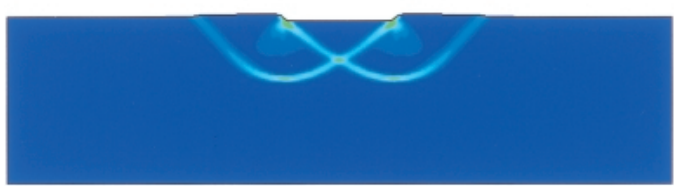

(b) Settlement $20 \mathrm{~cm}$

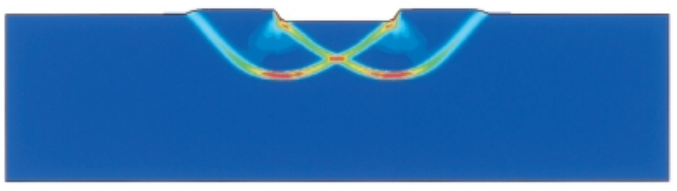

(c) Settlement $35 \mathrm{~cm}$
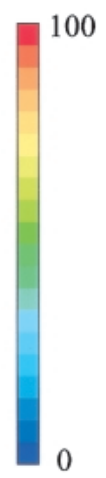

$\varepsilon_{s}(\%)$

Fig. 4. Shear strain distributions (less structured soil)

Fig. 5. Shear strain distributions (highly structured soil)

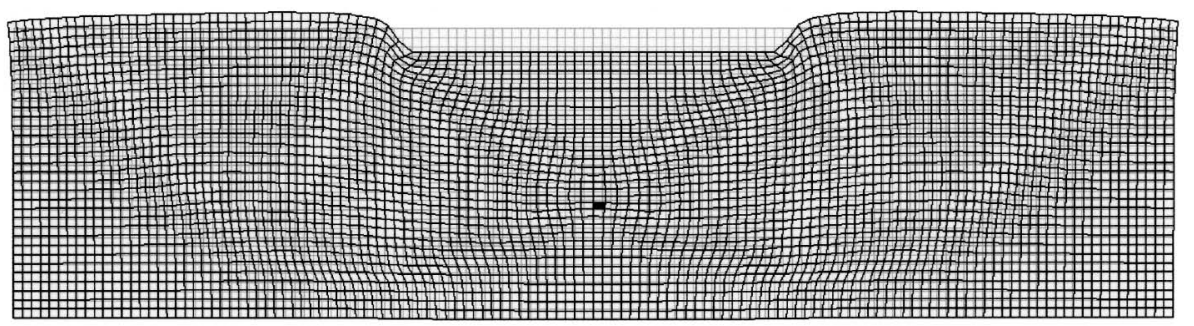

Soil deformation in vicinity of foundation and observed element (settlement $35 \mathrm{~cm}$ )
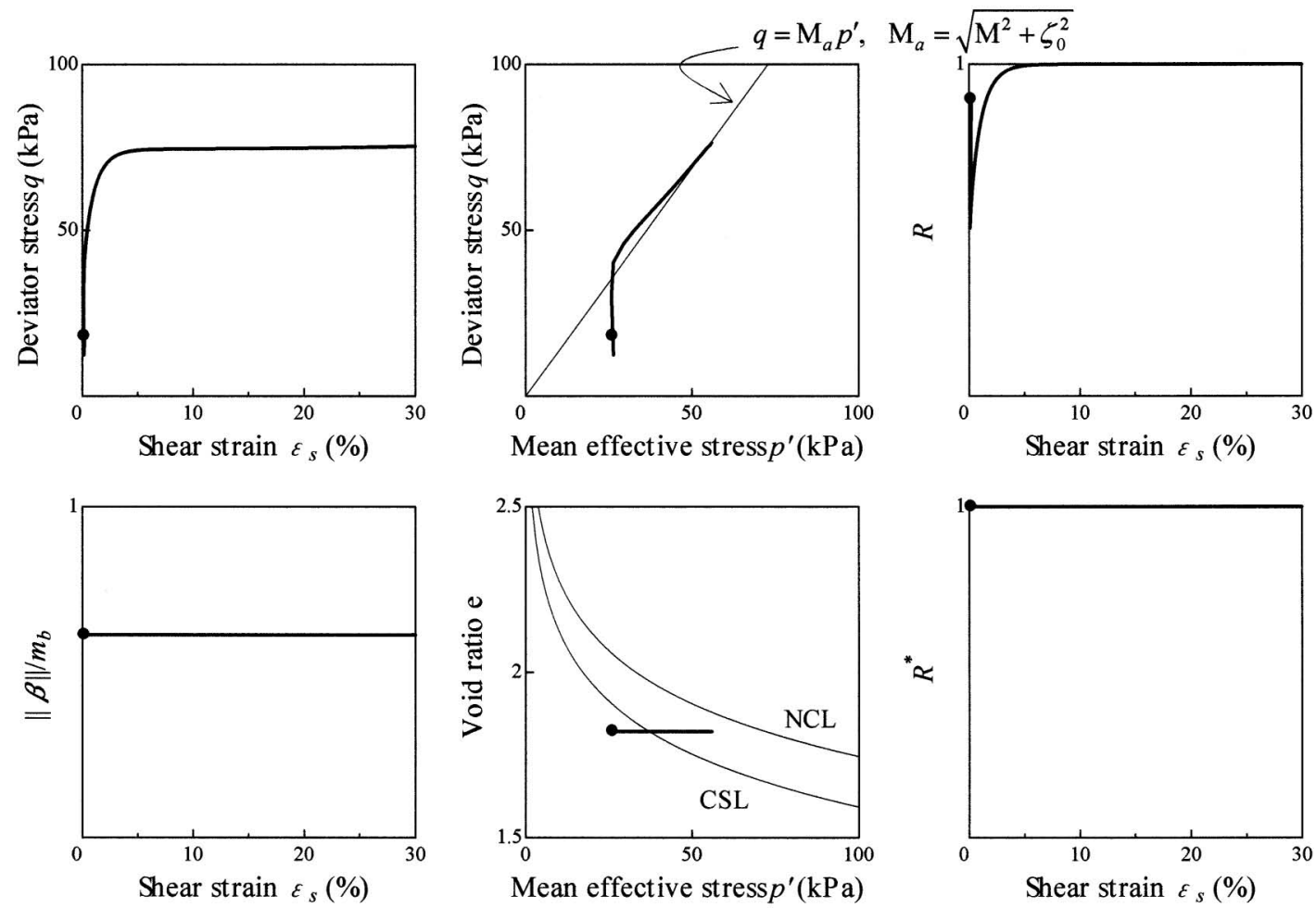

Soil element behaviors $(\cdot$ initial state)

Fig. 6. Soil element showing perfectly plastic behavior (less structured soil) 


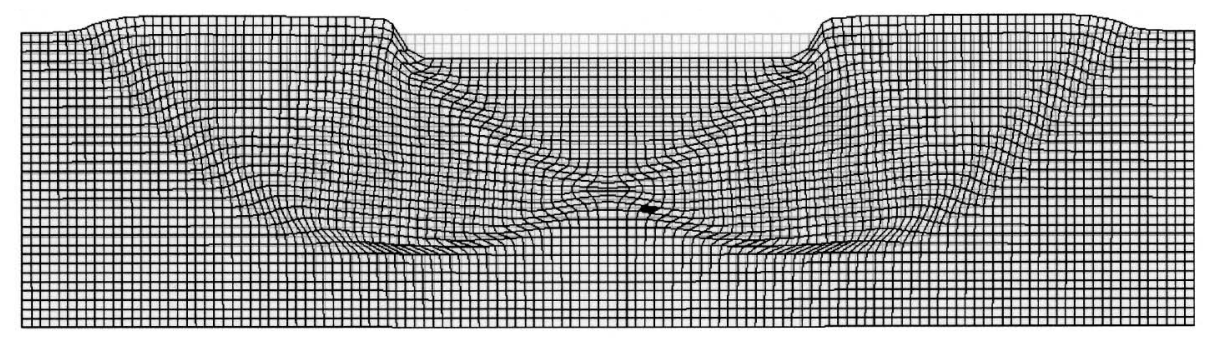

Soil deformation in vicinity of foundation and observed element (settlement $35 \mathrm{~cm}$ )
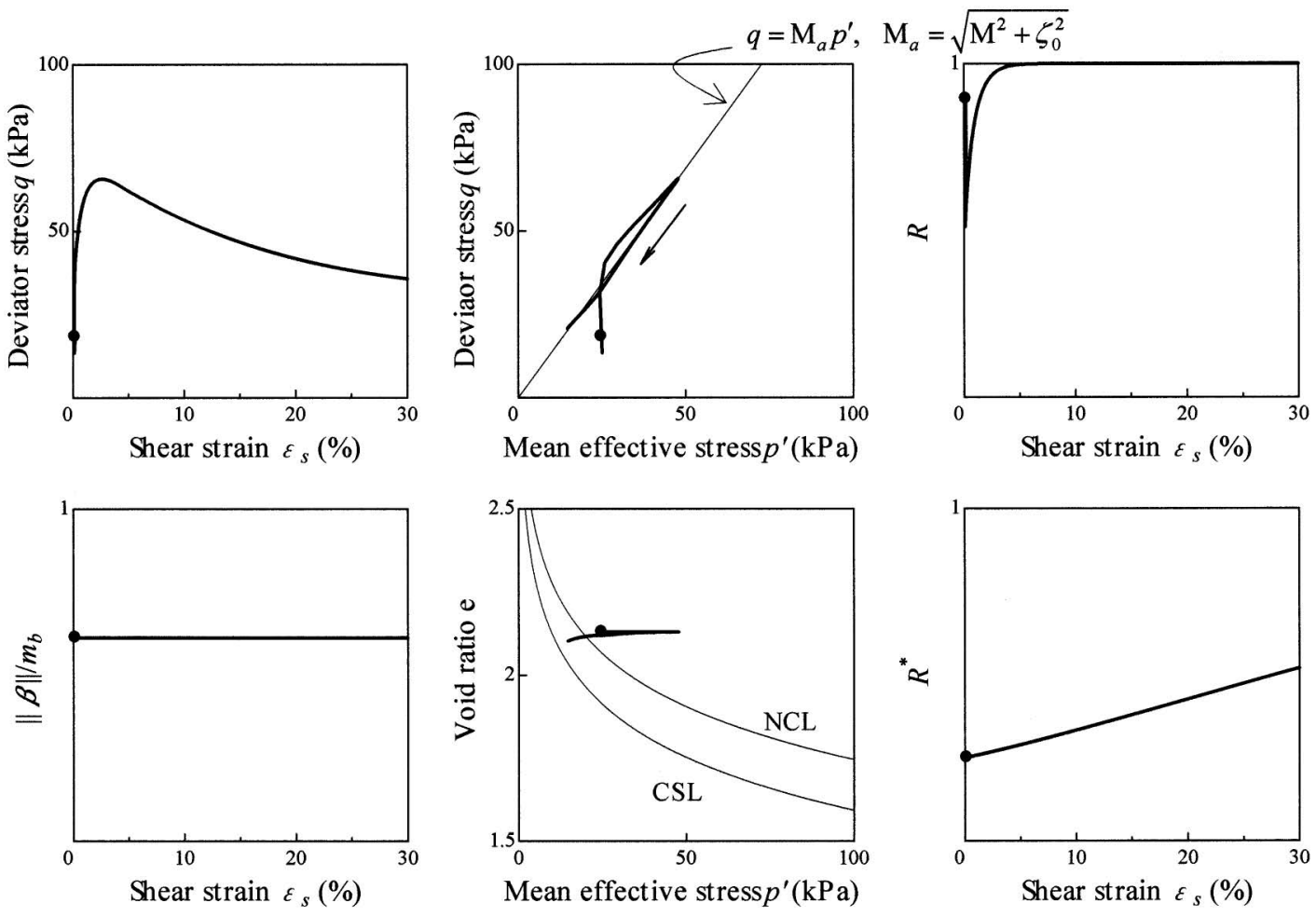

Soil element behaviors $(\cdot$ initial state)

Fig. 7. Soil element showing softening behavior together with plastic compression (highly structured soil)

vertical load follows an uninterrupted path of ascent. The reason for this is that even though perfectly plastic behavior sets in at the element level, we are dealing here with a progressive change in the geometrical shape of the whole soil. Indeed, from Fig. 4, showing the shear strain distributions for the remolded soil, it is possible to observe the support role played by the earth immediately adjacent to the foundation raising itself into a "counterweight fill", in response to the nearby loading. At the same time, as can be seen from the shear strain distribution in the structured soil (Fig. 5), the strain is remarkably localized with the occurrence of so-called 'slips,' so that in effect the area of analysis stays confined to the vicinity of the foundation. Also, even when the structured clay is in an undrained condition, the softening behavior displayed at the element level is enough to overcome the effect of the geometrical change in shape and produce a temporary drop in the load. Compared with the case analyzed by Prandtl, in admittedly different conditions (Prandtl, 1921), the area of slip in the present case is small. The soil

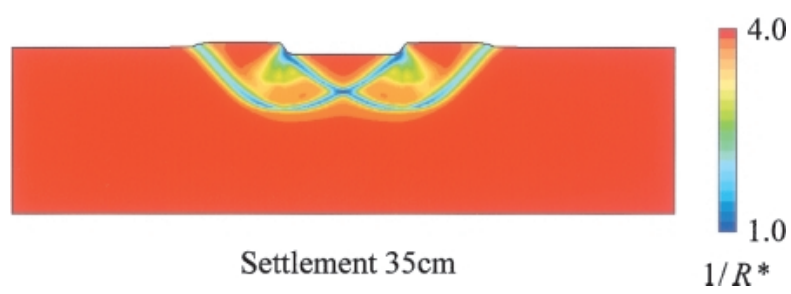

Fig. 8. State of structured decay in vicinity of "slip line" (highly structured soil)

element behaviors are shown in Fig. 6 for the remolded soil and in Fig. 7 for the structured one (the deformation mesh in Figs. 6 and 7 is selected from the finest part of the mesh shown in Fig. 1. The element particularly attended to is blackened. The same procedure is followed in Fig. 25). Both soils initially show an overconsolidation behavior (plastic expansion accompanied by hardening). This is the effect of removing the surcharge load before the start of the bearing capacity calculation. However, 

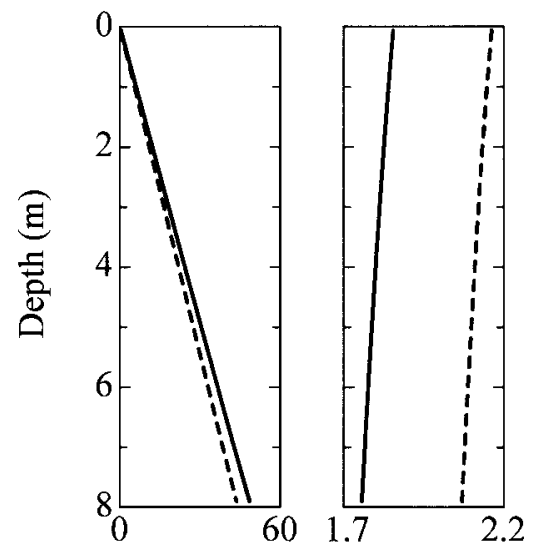

$\sigma{ }_{\mathrm{v}}^{\prime}(\mathrm{kPa})$

e

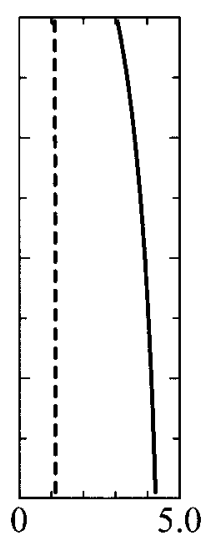

$1 / R$
----- Normally consolidated - Overconsolidated
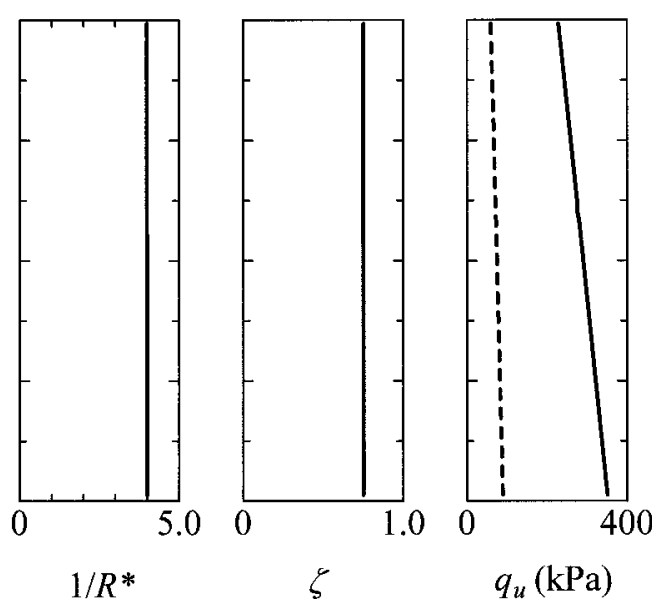

Fig. 9. Depth distributions just prior to loading (soils differing in overconsolidation ratio)

Table 3. Initial conditions in the soils (soils differing in overconsolidation ratio)

\begin{tabular}{lcc}
\hline & $\begin{array}{c}\text { Normally } \\
\text { consolidated }\end{array}$ & $\begin{array}{c}\text { Overcon- } \\
\text { solidated }\end{array}$ \\
\hline Degree of structure $1 / R_{0}^{*}$ & 4.0 & 4.0 \\
Overconsolidation ratio $1 / R_{0}$ & 1.0 & 4.0 \\
Degree of anisotropy $\zeta_{0}=\sqrt{3 / 2 \beta_{0} \cdot \beta_{0}}$ & 0.75 & 0.75 \\
Lateral pressure coefficient $k_{0}=\sigma_{h 0}^{\prime} / \sigma_{v 0}^{\prime}$ & 0.50 & 0.50 \\
\hline
\end{tabular}

the subsequent behaviors are totally different. While the elements in the remolded clay soil display a perfectly plastic behavior (Fig. 6), in the elements of the structured soil we notice a shift to a softening behavior together with plastic compression (Fig. 7). Figure 8 shows the distribution of degrees of structure $1 / R^{*}$ in the structured soil at the point in time where settlement has reached $35 \mathrm{~cm}$. The decay in structure is conspicuously apparent in the area of localized shear strain.

\section{Effects of Overconsolidation}

To show the effects that are introduced into bearing capacity problems by initial differences in the overconsolidation ratio, let us assume the two cases of soils in a normally consolidated state and in a state of overconsolidation prior to the removal of the surcharge load. Table 3 gives the initial conditions for these soils prior to the load removal, and Fig. 9 shows the depth distributions after removal and consolidation. The soils are structured in both cases. (The soil in the normally consolidated state prior to the removal of the surcharge load is the same as the highly structured soil in Table 2.)

The relation between load and settlement is shown in Fig. 10, and the distribution of the shear strains in Fig. 11. The area of failure is slightly larger in the overconsolidated soil. But more than this difference in the area of failure, what accounts especially for the higher peak load in overconsolided soil is clearly the difference in value of undrained shearing strength $q_{u}$ throughout the

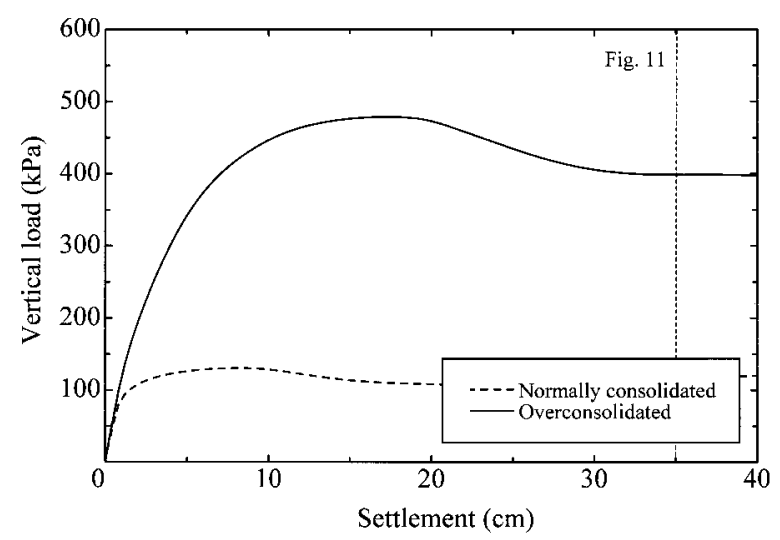

Fig. 10. Relation between load and settlement (effect of overconsolidation)
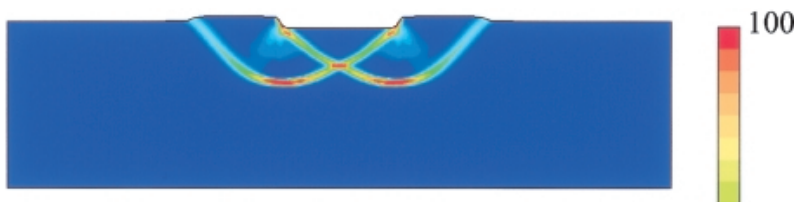

Normally consolidated

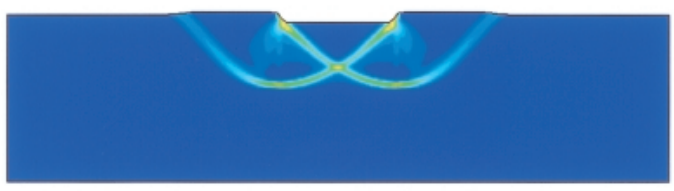

Overconsolidated $\varepsilon_{s}(\%)$

Settlement $35 \mathrm{~cm}$

Fig. 11. Shear strain distributions (effect of overconsolidation)

soil elements.

As is clear from Figs. 2 and 9, the above comparison is between two soils that differ in their void ratio distributions. But the difference in void ratio seems likely to have a particularly large influence on the bearing capacity. The 

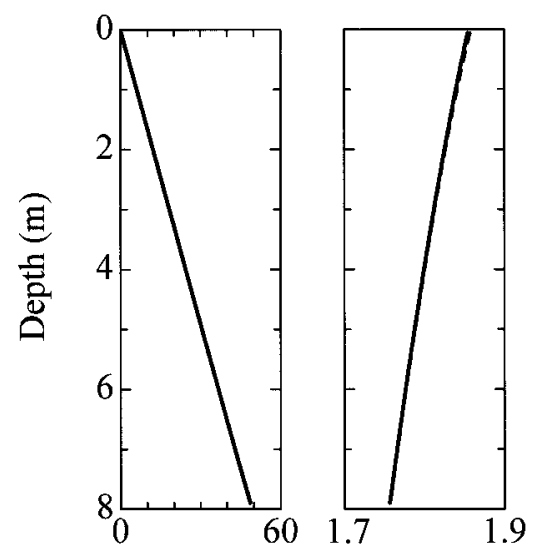

$\sigma{ }_{\mathrm{v}}^{\prime}(\mathrm{kPa})$

$\mathrm{e}$
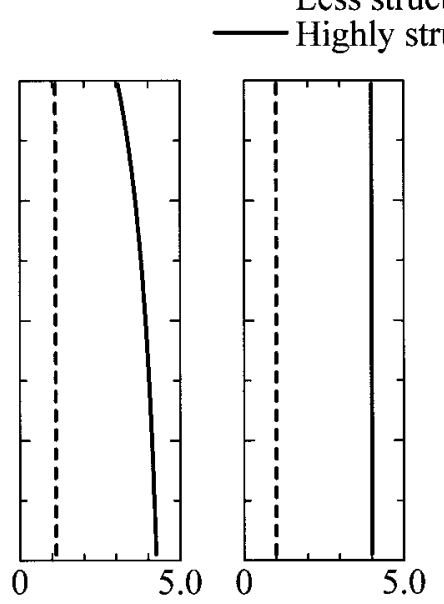

Fig. 12. Depth distributions just prior to loading (soils identical in void distribution)

Table 4. Initial conditions in the soils (soils identical in void ratio distribution)

\begin{tabular}{lcc}
\hline & $\begin{array}{c}\text { Less } \\
\text { structured, } \\
\text { Normally } \\
\text { consolidated }\end{array}$ & $\begin{array}{c}\text { Highly } \\
\text { structured, } \\
\text { Overcon- } \\
\text { solidated }\end{array}$ \\
\hline Degree of structure $1 / R_{0}^{*}$ & 1.0 & 4.0 \\
Overconsolidation ratio $1 / R_{0}$ & 1.0 & 4.0 \\
Degree of anisotropy $\zeta_{0}=\sqrt{3 / 2 \beta_{0} \cdot \beta_{0}}$ & 0.75 & 0.75 \\
Lateral pressure coefficient $k_{0}=\sigma_{h 0}^{\prime} / \sigma_{v 0}^{\prime}$ & 0.50 & 0.50 \\
\hline
\end{tabular}

next requirement, therefore, is to compare the effect of the degree of soil skeleton structure in conditions where the void ratio distribution is kept the same. For this purpose, let us compare a normally consolidated remolded soil (the less structured soil of Table 2) and a structured overconsolidated soil (the overconsolidated soil of Table 3). Table 4 shows the initial conditions prior to the removal of the surcharge load, and Fig. 12 the soil-depth distributions after the end of the load removal and consolidation. The void ratio distributions in the two soils prior to load removal are perfectly identical, and those following unloading and consolidation are close to identical also.

Figure 13 shows the load-settlement relation, and Fig. 14 the shear strain distributions. As can be seen, the bearing capacity is obviously larger in the structured overconsolidated soil. If we now make another comparison focusing on the degree of structure, we find that where we take overconsolidation ratios as our base of alignment, as above in Fig. 3, a higher degree of structure in the soil makes for a larger void ratio and a smaller bearing capacity, whereas if it we align void ratios, as in Fig. 13, a higher degree of structure makes for a larger overconsolidation ratio and hence also a greater bearing capacity. However, alignment based on void ratios will naturally make no difference to the fact that an area of pronounced strain localization appears in soils that are highly structured (Fig. 14).

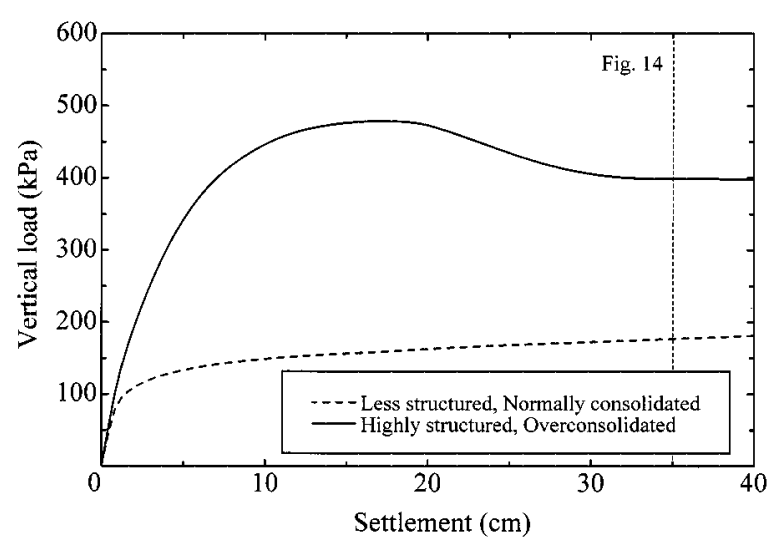

Fig. 13. Relation between load and settlement (soils identical in void ratio distribution)
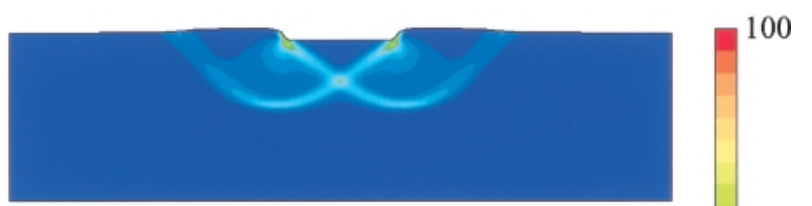

Less structured, Normally consolidated

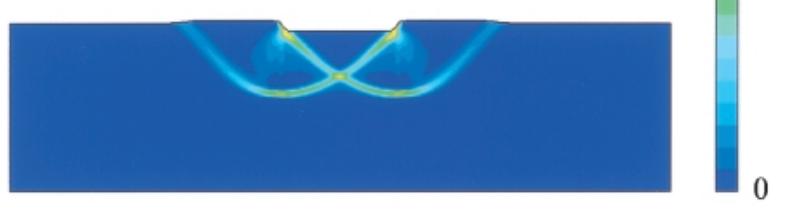

Highly structured, Overconsolidated

Settlement $35 \mathrm{~cm}$

Fig. 14. Shear strain distributions (soils identical in void ratio distribution)

\section{Effects of Initial Anisotropy}

In naturally deposited structured soils it is common for anisotropy to be well developed. We next look at some comparisons showing the effects of the presence or 


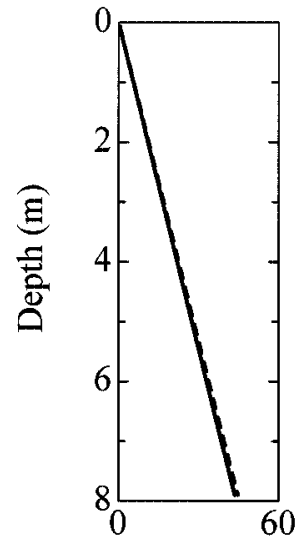

$\sigma^{\prime}{ }_{\mathrm{V}}(\mathrm{kPa})$

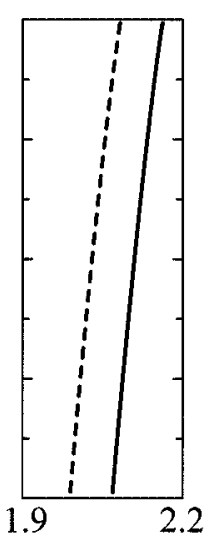

e

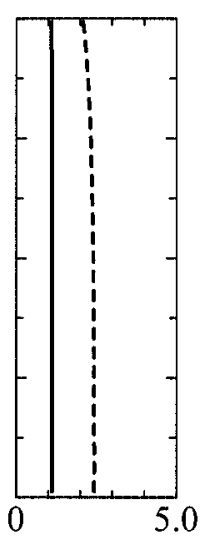

$1 / R$
---- Without initial anisotropy

- With initial anisotropy

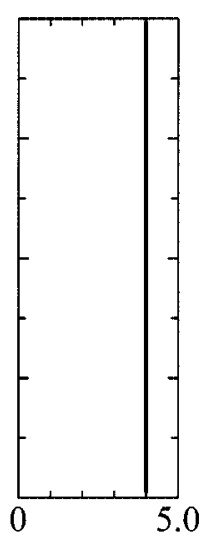

$1 / R^{*}$
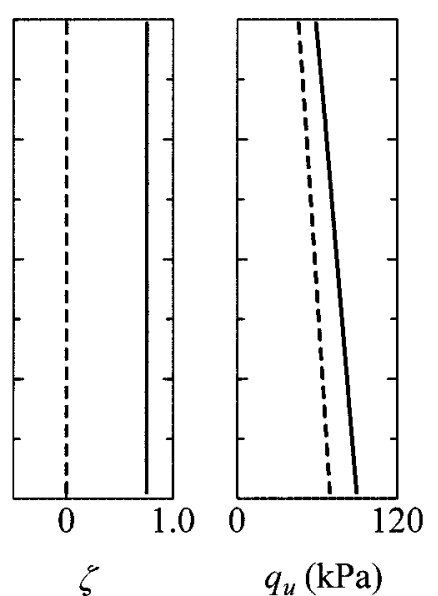

Fig. 15. Depth distributions just prior to loading (soils differing in initial anisotropy)

Table 5. Initial conditions in the soils (soils differing in initial degree of anisotropy)

\begin{tabular}{lcc}
\hline & $\begin{array}{c}\text { Without } \\
\text { initial } \\
\text { anisotropy }\end{array}$ & $\begin{array}{c}\text { With } \\
\text { initial } \\
\text { anisotropy }\end{array}$ \\
\hline Degree of structure $1 / R_{0}^{*}$ & 4.0 & 4.0 \\
Overconsolidation ratio $1 / R_{0}$ & 1.0 & 1.0 \\
Degree of anisotropy $\zeta_{0}=\sqrt{3 / 2 \beta_{0} \cdot \beta_{0}}$ & 0.0 & 0.75 \\
Lateral pressure coefficient $k_{0}=\sigma_{h 0}^{\prime} / \sigma_{v 0}^{\prime}$ & 0.50 & 0.50 \\
\hline
\end{tabular}

absence of initial anisotropy (i.e., for the two cases $\zeta_{0}=$ $\sqrt{3 / 2}\left\|\beta_{0}\right\|=0$ and $\zeta_{0} \neq 0$ ). (In the anisotropic state, $\zeta_{0} \neq 0$, the SYS Cam-clay model becomes non-coaxial.) Table 5 shows the initial conditions prior to removal of the surcharge load, and Fig. 15 shows the soil-depth distributions after removal and consolidation. In each case the soil is structured, and in a normally consolidated state prior to the removal of the surcharge load. (The soil possessing initial anisotropy is the same as the highly structured soil in Table 2.) Figure 16 shows the influence of the cutting angle on results of an unconfined compression test performed on samples of the soil possessing initial anisotropy, as expressed by constitutive equation responses. (Note: this is assumed to be an ideal sampling from a depth of $4 \mathrm{~m}$ (Noda et al., 2005).) The various angles shown in the figure key denote the angles formed between the sedimentation direction and the axis of the cylindrical test piece, so that $90^{\circ}$ refers to a piece cut from the clay horizontally. (The method of varying the cutting angle is indicated in APPENDIX C.) The smaller the cutting angle, the larger the unconfined compression strength is found to be. Results of the same tendency have often been reported (e.g., Mikasa et al., 1987), and show that a soil of the kind assumed possesses anisotropy.

The relation between load and settlement is shown in Fig. 17, and the shear strain distributions are given in Fig. 18. It can be seen that a soil of pronounced initial anisotropy will show a smaller area of slip, as well as a

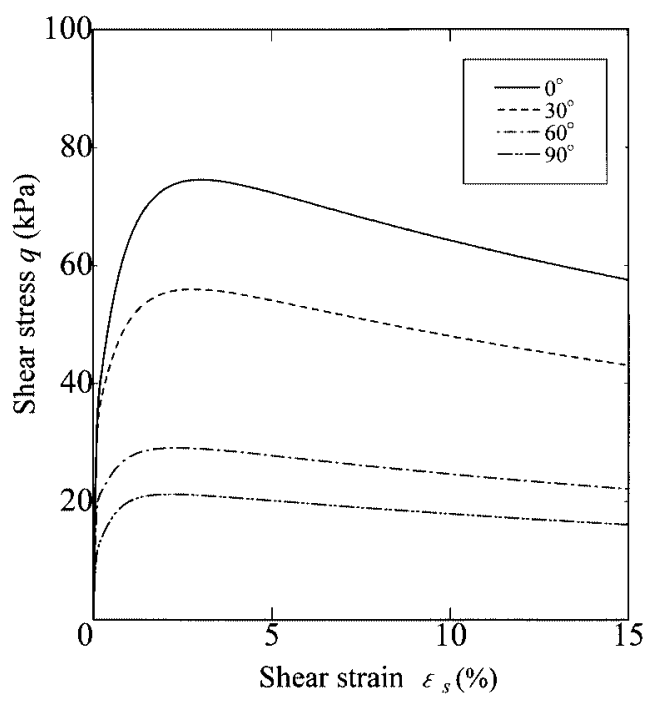

Fig. 16. Effect of test piece cutting angle (unconfined compression test)

smaller load peak. This result matches a finding obtained more than 10 years ago from a soil-water coupled rigid plastic analysis by Asaoka and Kodaka (1992).

\section{Effects of Initial Imperfections}

The above results are for soils completely free of initial imperfections. We next examine a case in which such an imperfection is present. Let us posit a case in which a load of $0.981 \mathrm{kN} / \mathrm{m}$ is applied to a unit-length section in the direction of a nodal point lying $1 \mathrm{~m}$ further to the left of left edge of the foundation. (Loading is for 1 second, at the end of which time the bearing capacity calculation is immediately performed.) The soil assumed is of the highly structured sort shown in Table 2 . The load-settlement relation is as given in Fig. 19, and the shear strain distributions, allowing for the posited imperfection, are as in Fig. 20. A soil of this sort with an initial imperfection will exhibit an asymmetrical deformation mode, with 


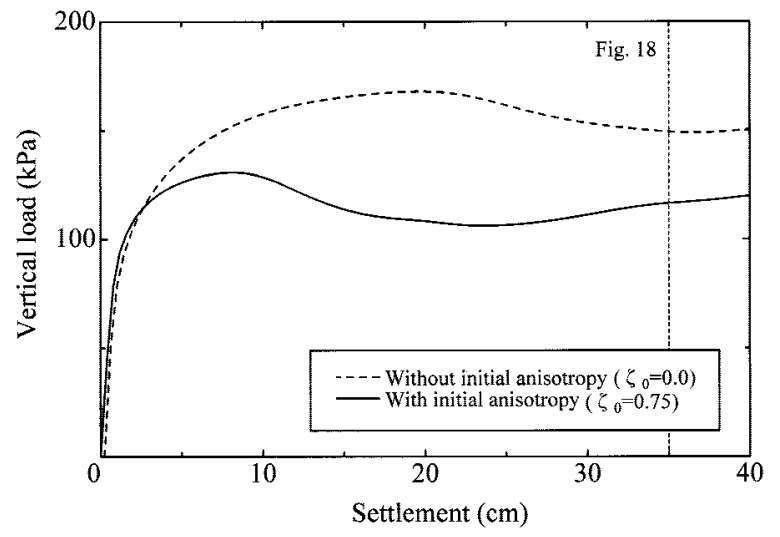

Fig. 17. Relation between load and settlement (effect of initial anisotropy)

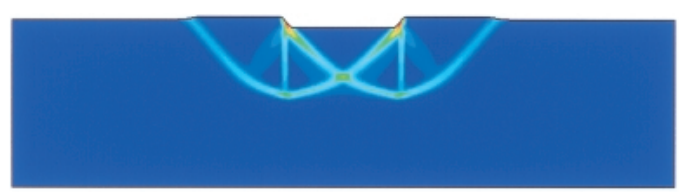

Without initial anisotropy $\left(\zeta_{0}=0.0\right)$

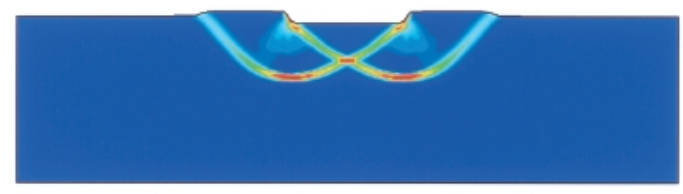

With initial anisotropy $\left(\zeta_{0}=0.75\right)$

0

$\varepsilon_{s}(\%)$

Settlement $35 \mathrm{~cm}$

Fig. 18. Shear strain distributions (effect of initial anisotropy)

a "bifurcation" from the regular path followed by symmetrical deformation. As can be seen, this will mean that for a time the load becomes smaller than in the symmetrical mode ("imperfection-sensitive bifurcation behavior' (Asaoka and Noda, 1995a)). In practice there are bound to be initial imperfections in soils, whether geometrical or material in origin. Whatever causes them, it has to be expected that, due to tiny imperfections, an asymmetrical mode of deformation will constantly occur.

Figure 21 shows the shear strain distribution for the same initial imperfection, but posited for a remolded clay soil of the sort shown in Table 2. Unlike in the case of the structured soil, it is found that the deformation here is more or less symmetrical. The load-settlement relation also shows no "bifurcation" from the path that would be taken if no imperfection were present. This result shows that exactly the same kind of imperfection may or may not produce a bifurcation, depending on the degree of structuring in the soil concerned.

\section{Effects of Soil-water Coupling}

The above calculation was for a case of rapid loading ( $\fallingdotseq$ perfectly undrained) with next to no occurrence of pore water migration within the soil. In order to establish the calculation effects of the soil-water coupling, let us

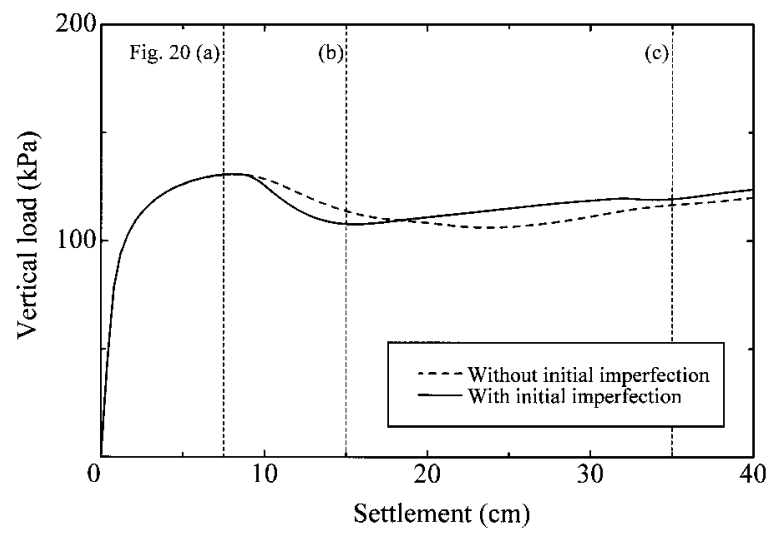

Fig. 19. Relation between load and settlement (effect of initial imperfection)

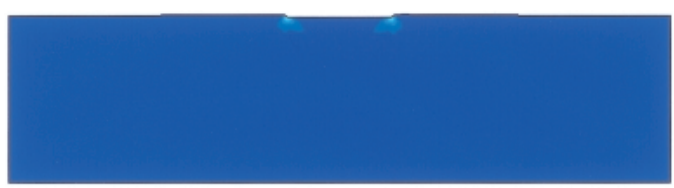

(a) Settlement $7.5 \mathrm{~cm}$

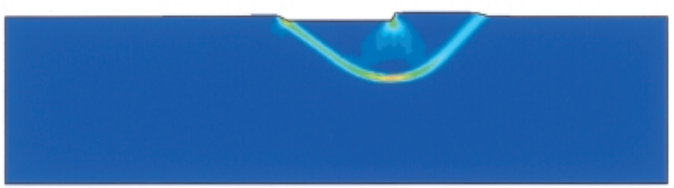

(b) Settlement $15 \mathrm{~cm}$

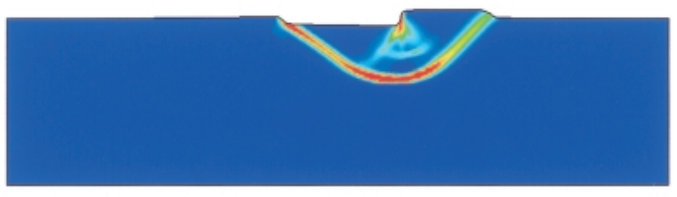

(c) Settlement $35 \mathrm{~cm}$

$\varepsilon_{s}(\%)$

Fig. 20. Shear strain distributions (with initial imperfection, highly structured)
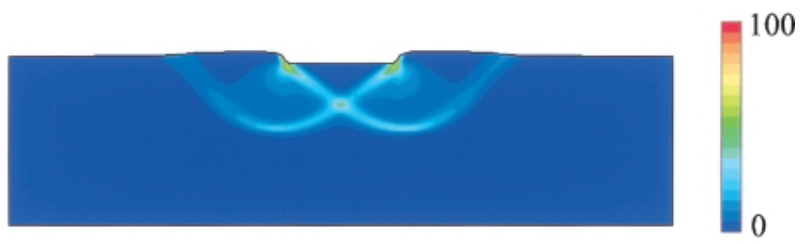

Settlement $35 \mathrm{~cm}$

$\varepsilon_{s}(\%)$

Fig. 21. Shear strain distributions (with initial imperfection, less structured)

also analyze three cases of forced vertical displacement at rates of first $1.0 \times 10^{-3} \mathrm{~cm} / \mathrm{sec}$, and then of $4.0 \times 10^{-6}$ $\mathrm{cm} / \mathrm{sec}$ and $1.0 \times 10^{-6} \mathrm{~cm} / \mathrm{sec}$, to show the partial draining effect this has on the bearing capacity characteristics. The initial conditions are as set out for the highly structured soil in Table 2. The load-settlement relation is shown in Fig. 22, and the shear strain distributions are in Fig. 23. The peak strength is greater at $4.0 \times 10^{-7} \mathrm{~cm} / \mathrm{sec}$ 


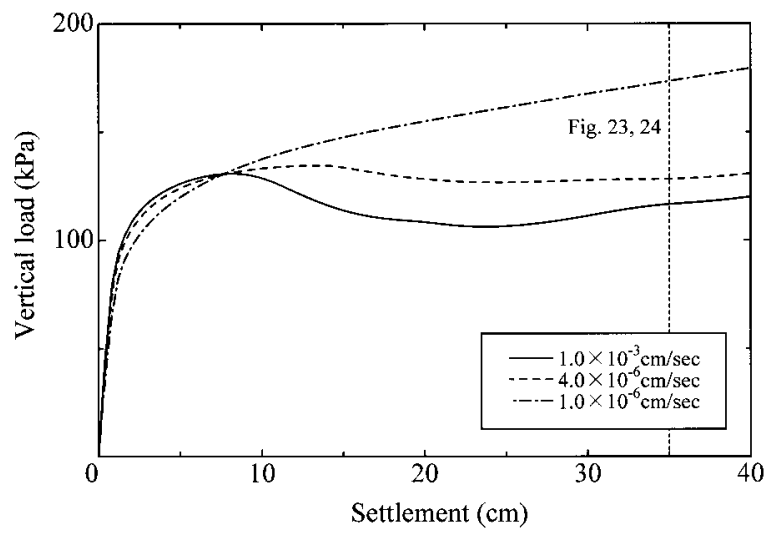

Fig. 22. Relation between load and settlement (effect of partial draining)

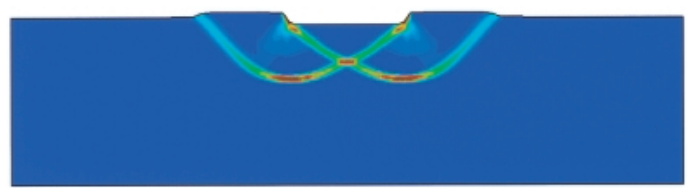

$1.0 \times 10^{-3} \mathrm{~cm} / \mathrm{sec}$

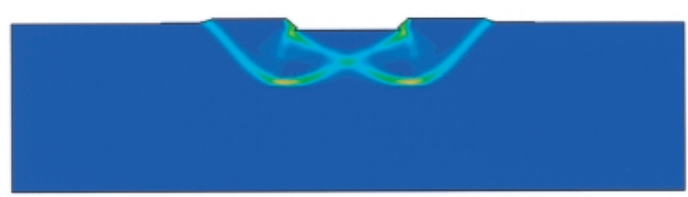

$4.0 \times 10^{-6} \mathrm{~cm} / \mathrm{sec}$

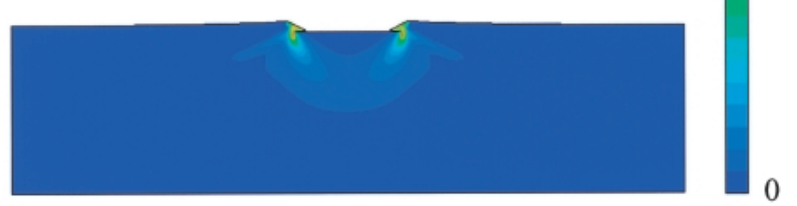

$1.0 \times 10^{-6} \mathrm{~cm} / \mathrm{sec}$

$\varepsilon_{s}(\%)$

Settlement $35 \mathrm{~cm}$

Fig. 23. Shear strain distributions (effect of partial draining)

than at $1.0 \times 10^{-3} \mathrm{~cm} / \mathrm{sec}$, but when the rate is slowed down to $1.0 \times 10^{-7} \mathrm{~cm} / \mathrm{sec}$ the compression becomes outstandingly large and the load shows no peak value. Similar areas of shear strain localization can be observed both at $4.0 \times 10^{-7} \mathrm{~cm} / \mathrm{sec}$ and at $1.0 \times 10^{-3} \mathrm{~cm} / \mathrm{sec}$, but at the slower rate of $1.0 \times 10^{-7} \mathrm{~cm} / \mathrm{sec}$ it becomes impossible to detect any clear area of failure. Figure 24 shows the distributions of change in the void ratios, from the commencement of loading on. It is important to observe in this figure whether expression or compression of the soil is visible in the area of the so-called 'slip line.' A clear occurrence of compression can be seen in the area of shear strain localization (a compaction band) at the $4.0 \times 10^{-6}$ $\mathrm{cm} / \mathrm{sec}$ loading rate. As shown in Fig. 25, it is actually possible at this rate to find soil elements on the slip line in which softening is taking place even while draining is in progress.

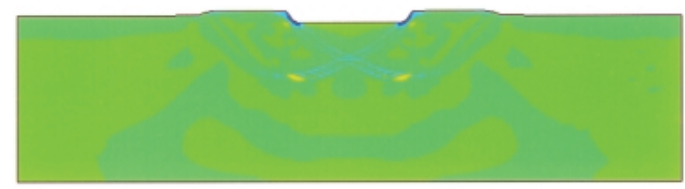

$1.0 \times 10^{-3} \mathrm{~cm} / \mathrm{sec}$

(Compression)
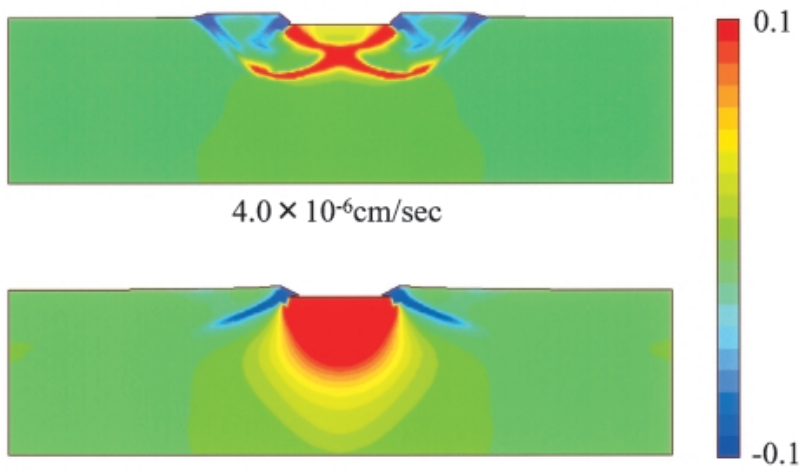

$1.0 \times 10^{-6} \mathrm{~cm} / \mathrm{sec}$

(Expansion)

Settlement $35 \mathrm{~cm}$

$\Delta \mathrm{e}$

Fig. 24. Distribution of change in void ratios (effect of partial draining)

\section{Influence of the Size of the Area Analyzed}

Since, in many soil problems, the size and shape of the object of analysis are not self-evident, the way of setting the area to be analyzed is one point that needs deciding. Here we describe the effect of the size of area analyzed, in conditions where the depth of the area is varied as shown in Fig. 26. The soil chosen for the calculation is the same as the one that is shown as more highly structured in Table 2. The relation between the load and the displacement is given in Fig. 27. The differences in each case are extremely small. The same is found if we look at the distributions of behaviors such as shear strain. In general, while solutions obtained from an elastic analysis are always affected by the way of setting the area analyzed, in a rigid plastic analysis if the analysis area is set above a certain extent a single unchanging collapse mechanism and limit load will be found irrespective of the setting adopted. The results here indicate that as the load approaches its peak, even for elasto-plastic analyses in which the plastic part of the deformation is more prominent, relatively speaking, than the elastic part, solutions will be obtained that show no effect from the extent of the area analyzed, just as in the case of the rigid plastic analysis. For the present study, with this in mind, a sufficiently large analysis area was chosen to ensure that no appreciable difference would have arisen in the results even if the area had been still further increased.

\section{Influence of the Mesh Size}

Finally, let us see what effect the mesh size has on the analysis results. Two different types of finite element mesh are presented for comparison, as shown in Fig. 28. Mesh A is the one actually used for the calculations in this study, while mesh B has double the number of divisions 


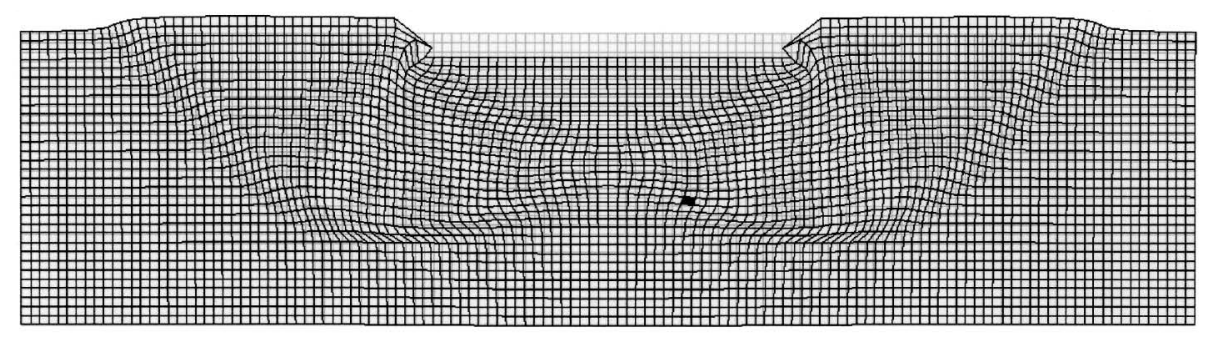

Soil deformation in vicinity of foundation and observed element (settlement $35 \mathrm{~cm}$ )
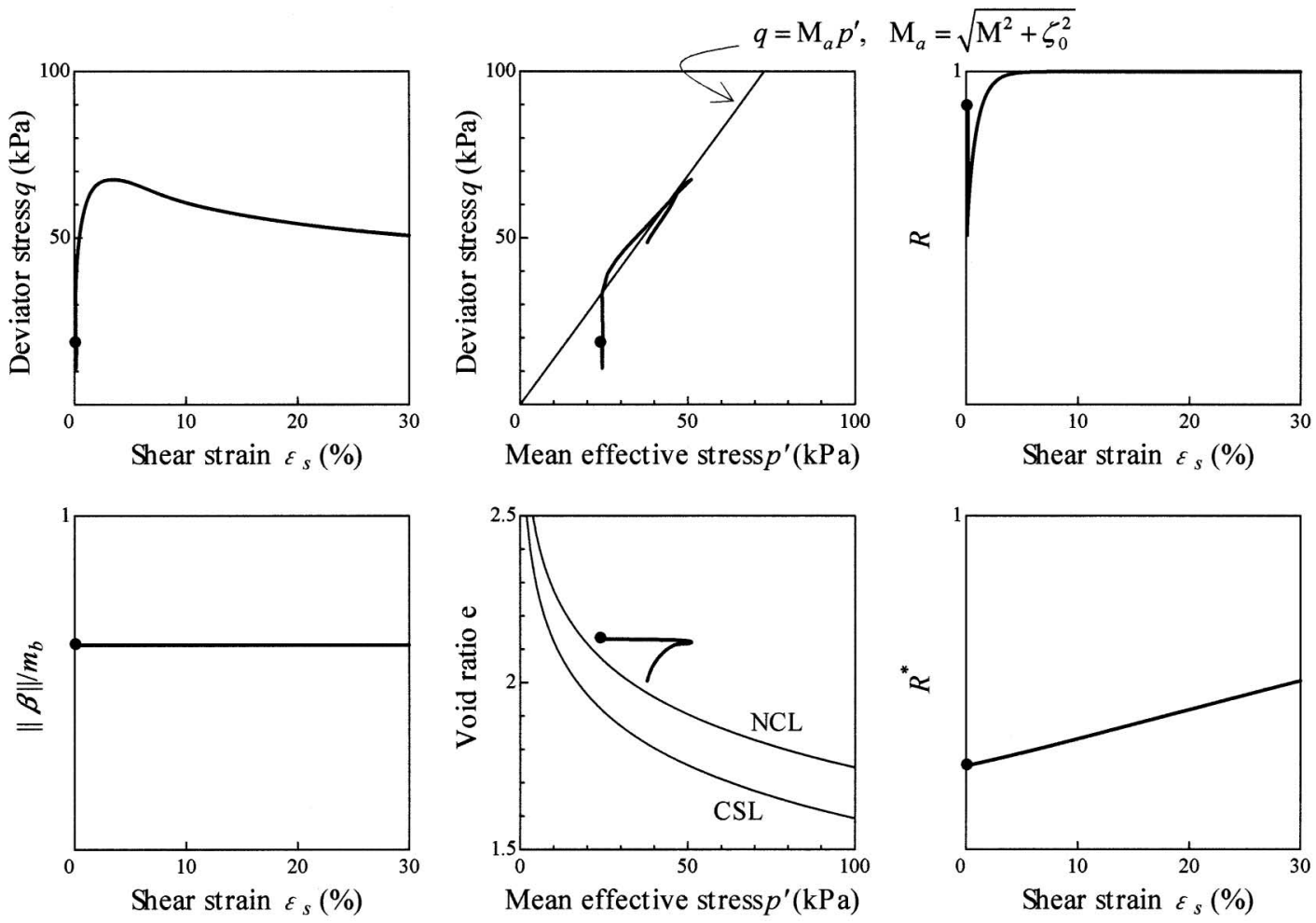

Soil element behaviors $(\cdot$ initial state)

Fig. 25. Soil element showing softening behavior together with compression (loading rate: $4.0 \times 10^{-6} \mathrm{~cm} / \mathrm{sec}$ )

in both the vertical and the horizontal direction. As the mesh is made finer an excessive accumulation of numerical rounding differences occurs, and in some cases these differences lead to imperfections that cause asymmetrical deformation results even when the boundary conditions are given as symmetrical. Here, therefore, we undertake a comparison of one such case with another in which an initial imperfection was assumed from the start. The method of assigning the initial imperfection is the same as described just above, and the soil selected for the calculation is the same as the highly structured soil shown in Table 2.

Figure 29 shows the load-settlement relations, and Fig. 30 the shear strain distributions. From the large number of calculations undertaken by the authors in addition to the example presented here, it appears in general that the finer the mesh size used, the more concentrated the degree of shear strain localization, and the more pronounced the sharpness of the slip line described. Also, a greater fineness of mesh size results in a sharper fall in the load magnitude, although the effect on the level of the peak load is not particularly large.

One of the aims of this study, as was said at the beginning, was to investigate the effects of the three factors of structure, overconsolidation and anisotropy on the bearing capacities of clay soils. But seeing how this use of mesh B leads to a loss in symmetry even where no initial imperfection exists in the soil as given, there may always be a possibility of confusion as to whether a result obtained is due to the effect of the soil skeleton structure, or to the influence of the mesh size. There is no fear of such confusion in the present study, however, and the mesh chosen is also sufficiently fine to ensure that no large difference will appear in the peak load even when the fineness is reduced.

\section{CONCLUSION}

In the study, a soil-water coupled finite element deformation analysis was performed on a bearing capacity 
problem, using the elasto-plastic SYS Cam-clay model to describe the working of the soil skeleton structure. On the problem assumption of a forced vertical displacement being applied to a rigid foundation possessing friction, investigations were pursued concerning the effects of the soil skeleton structure and its workings on the bearing capacity characteristics of the soil, and concerning the
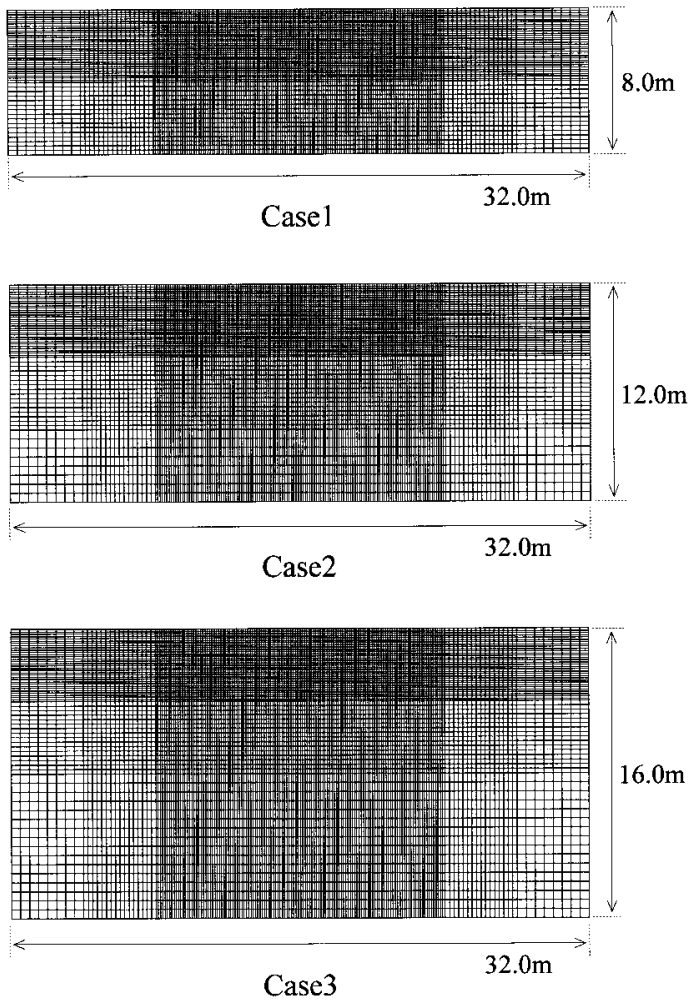

Fig. 26. Three meshes differing in the area of region analyzed further effects of the soil-water coupling, as well as other factors. The findings are laid out below.

(1) In the elasto-plastic finite deformation analysis for the moment-by-moment changes in the geometrical shape of the soil, it is possible to take account of the role of "counterweight fill" on either side of the foundation. If this is done, the results show the load following a path of continuous ascent even when a remolded clay would show a perfectly plastic behavior at element level. In the case of a highly structured soil, on the other hand, a softening behavior is displayed at the element level, and as this balances out the effect of the geometric shape changing a peak appears in the load-settlement relation, with a further rise thereafter. Also, in the highly structured soil, a pronounced localization of strain-the so called 'slip' phenomenon-occurs, so that the analysis area is effectively confined to the vicinity of the foundation.

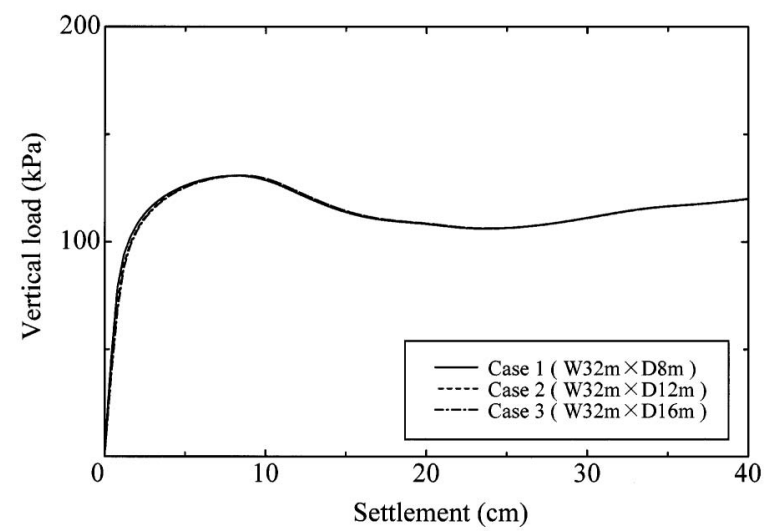

Fig. 27. Relation between load and settlement (influence of the size of the area analyzed)

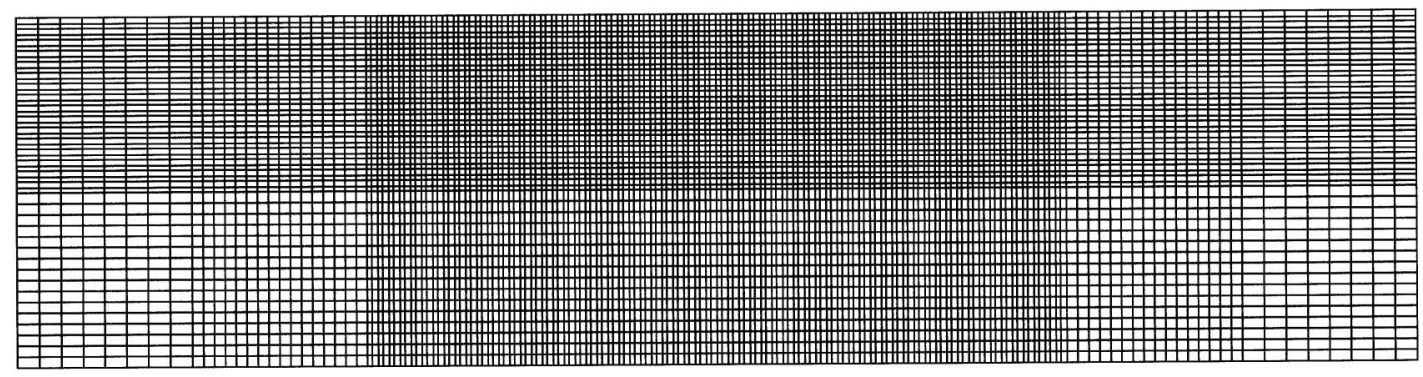

Mesh A $(176 \times 48$ elements $)$

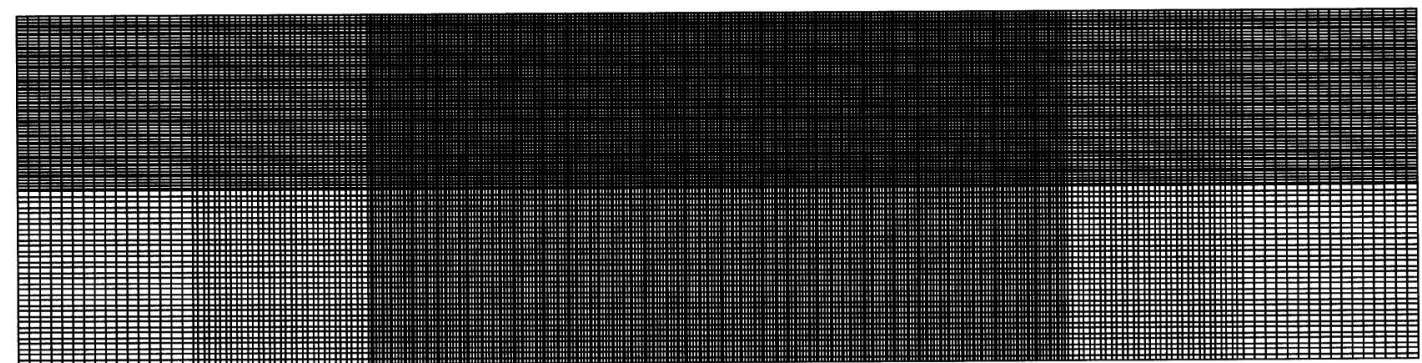

Mesh B $(352 \times 96$ elements $)$

Fig. 28. Two meshes of differing fineness 


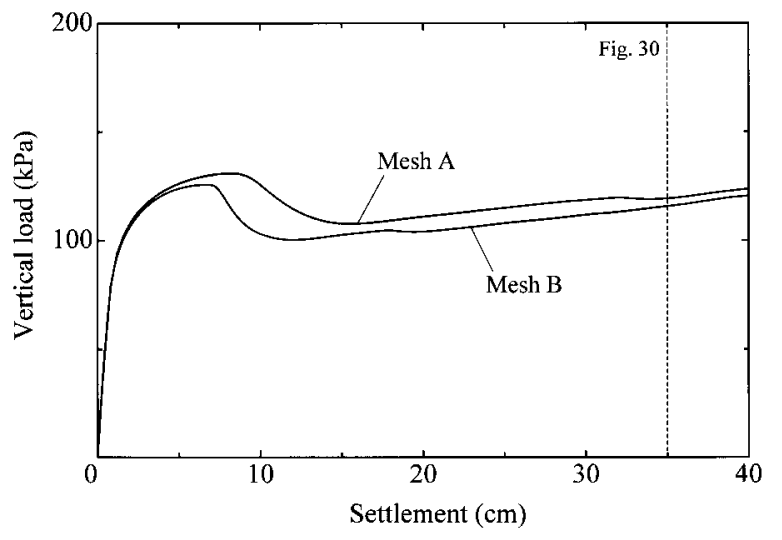

Fig. 29. Relation between load and settlement (influence of mesh size)
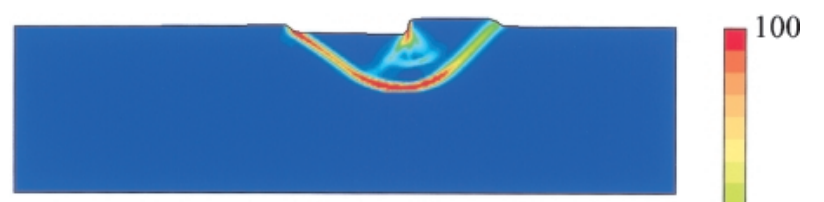

Mesh A

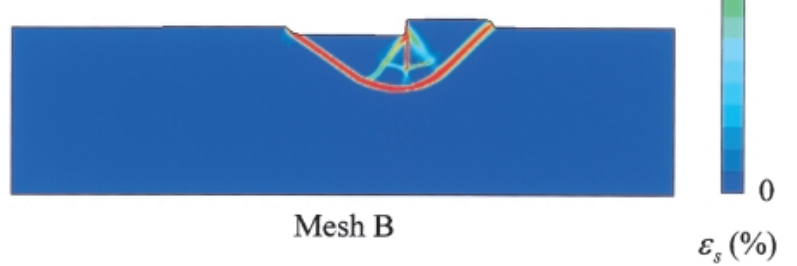

Settlement $35 \mathrm{~cm}$

Fig. 30. Shear strain distributions (influence of mesh size)

(2) In soils of an approximately equal degree of structure, the peak load will be larger, the greater the overconsolidation ratio (OCR), since the undrained shearing strength displayed by the constituent elements is large.

(3) In cases where the OCR is approximately the same, a more structured soil will have a greater void ratio, and therefore a lower bearing capacity. In soils having the same void ratio distribution, on the other hand, the more structured soil will be in a state of greater overconsolidation and will accordingly have a higher bearing capacity. (4) As shown in a soil-water coupled rigid elasto-plastic analysis by Asaoka and Kodaka (1992), in a soil possessing initial anisotropy a decrease in the area of failure leads to a simultaneous decline in the peak load, as compared with an initially isotropic soil.

(5) In the kind of case in which a highly structured soil possesses an initial imperfection, an asymmetrical circular slip mode can be expected to appear. When this happens, the deformation path will bifurcate from the one followed in symmetrical deformation, and a larger decrease will also be found in the load. A soil with a low degree of structure, however, will go on showing a roughly symmetrical deformation mode even when the initial imperfection assigned to it is the same. The degree of skeleton structure in a soil also has an influence on the imperfection sensitivity of its bearing capacity.
(6) If the loading rate on a soil is changed from a very rapid rate ( $\fallingdotseq$ perfectly undrained) at which virtually no internal migration of pore water can take place to a rate that is slower, the load peak will gradually increase owing to the partial draining effect. If the loading rate is slowed down still further, a point will finally come at which no more decline is observed in the load and it is impossible to make out a distinct area of failure. At a certain rate of loading, a clear "compaction band" can also be observed, resulting from a decay of structure in the area of strain localization.

(7) For elasto-plastic analysis, if the area to be analyzed is set somewhat above a certain particular size, then as in a rigid plastic analysis, the size of this area will cease to have an appreciable effect on the solution obtained.

(8) The finer the mesh size adopted, the more noticeable will be the decline in the load, and at the same time the sharper will tend to be the slip line described.

\section{REFERENCES}

1) Asaoka, A. and Ohtsuka, S. (1986): The analysis of failure of a normally consolidated clay foundation under embankment loading, Soils and Foundations, 26(2), 47-59.

2) Asaoka, A. and Ohtsuka, S. (1987): Bearing capacity analysis of a normally consolidated clay foundation, Soils and Foundations, 27(3), 58-70.

3) Asaoka, A. and Kodaka, T. (1992): Bearing capacity of foundations on clays by the rigid plastic finite element model, Proc. 4th Int. Symp. Num. Models Geomech.-NUMOG IV, 839-849.

4) Asaoka, A., Nakano, M. and Noda, T. (1994): Soil-water coupled behaviour of saturated clay near/at critical state, Soils and Foundations, 34(1), 91-106.

5) Asaoka, A. and Noda, T. (1995a): Imperfection-sensitive bifurcation of Cam-clay under plane strain compression with undrained boundaries, Soils and Foundations, 35(1), 83-100.

6) Asaoka, A., Nakano, M., Fernando, G. S. K. and Nozu, M. (1995b): Mass permeability concept in the analysis of treated ground with sand drains, Soils and Foundations, 35(3), 43-53.

7) Asaoka, A., Nakano, M. and Noda, T. (1997): Soil-water coupled behaviour of heavily overconsolidated clay near/at critical state, Soils and Foundations, 37(1), 13-28.

8) Asaoka, A., Nakano, M. and Noda, T. (1998a): Super loading yield surface concept for the saturated structured soils, Proc. 4th Eur. Conf. Num. Meth. Geotech. Engrg. NUMGE98, 232-242.

9) Asaoka, A., Noda, T. and Kaneda, K. (1998b): Displacement/traction boundary conditions represented by constraint conditions on velocity field of soil, Soils and Foundations, 38(4), 173-181.

10) Asaoka, A., Nakano, M. and Noda, T. (2000): Superloading yield surface concept for highly structured soil behavior, Soils and Foundations, 40(2), 99-110.

11) Asaoka, A., Noda, T., Yamada, E., Kaneda, K. and Nakano, M. (2002): An elasto-plastic description of two distinct volume change mechanisms of soils, Soils and Foundations, 42(5), 47-57.

12) Green, A. E. and Naghdi, P. M. (1965): A general theory of an elastic-plastic continuum, Arch. Rat. Mech. Anal., 18, 251-281.

13) Hashiguchi, K. (1978): Plastic constitutive equations of granular materials, Proc. US-Japan Seminar on Continuum Mechanics and Statistical Approaches in the Mechanics of Granular Materials (eds. by Cowin, S. C. and Satake, M.), Sendai, JSSMFE, 321-329.

14) Hashiguchi, K. (1989): Subloading surface model in unconventional plasticity, Int. J. Solids and Structures, 25, 917-945.

15) Hashiguchi, K. and Chen, Z.-P. (1998): Elasto-plastic constitutive equations of soils with a subloading surface and rotational hardening, Int. J. Num. Anal. Meth. Geomech., 22, 197-227.

16) Ikeda, K., Yamakawa, Y. and Tsutsumi, S. (2003): Simulation and interpretation of diffuse mode bifurcation of elastoplastic solids, $J$. 
Mech. Phys. Solids, 51, 1649-1673.

17) Mikasa, M., Takada, N. and Ohshima, A. (1987): In situ strength anisotropy of clay by direct shear test, Proc. 8th Asian Reg. Conf. 1, 25-84.

18) Noda, T., Fernando, G. S. K. and Asaoka, A. (2000): Delayed failure in soft clay foundations, Soils and Foundations, 40(1), $85-97$.

19) Noda, T., Yamada, S. and Asaoka, A. (2005): Elasto-plastic behavior of naturally deposited clay during/after sampling, Soils and Foundations, 45(1), 51-64.

20) Prandtl, L. (1921): On the penetrating strength (hardness) of plastic construction materials and the strength of cutting edges, Zeit. Angew. Math. Mech., 1(1), 15-20.

21) Roscoe, K. H. and Burland, J. B. (1968): On the generalized stress-strain behaviour of 'wet' clay, Engineering Plasticity (eds. by Heyman, J. and Leckie, F. A.), Cambridge University Press, 535-609.

22) Sekiguchi, H. and Ohta, H. (1977): Induced anisotropy and time dependency in clays, Constitutive Equations of Soils, Proc. 9th ICSMFE, Spec. Session 9, Tokyo, 229-238.

23) Tamura, T., Kobayashi, S. and Sumi, T. (1984): Limit analysis of soil structure by rigid plastic finite element method, Soils and Foundations, 24(1), 34-42.

24) Yatomi, C., Yashima, A., Iizuka, A. and Sano, I. (1989a): General theory of shear bands formation by a non-coaxial Cam-clay model, Soils and Foundations, 29(3), 41-53.

25) Yatomi, C., Yashima, A., Iizuka, A. and Sano, I. (1989b): Shear bands formulation numerically simulated by a non-coaxial Cam-clay model, Soils and Foundations, 29(4), 1-13.

\section{APPENDIX A: THE SUPER/SUBLOADING YIELD SURFACE (SYS) CAM-CLAY MODEL}

Quantified Expression of Structure, Overconsolidation, Anisotropy, and Their Respective Evolution Rules

Naturally deposited soils, whether clayey or sandy, generally exist in a 'structured' and overconsolidated state. To describe the deformation behavior of a soil in this state, we have to start from the base of an elastoplastic model of a de-structured soil in a state of normal consolidation. Given that a soil in this unstructured and normally consolidated state still possesses anisotropy, we take for our 'base' in this paper the corrected Cam-clay model of Roscoe and Burland (1968) with the introduced addition of the rotational hardening concept of Sekiguchi and Ohta (1977), which treats stress parameter $\eta^{*}$ and its evolution rule as an expression of anisotropy. The degrees of structure and overconsolidation are then introduced and quantified by means of the two concepts of the superloading yield surface for structure (Asaoka et al., 1998a, 2000, 2002), and the subloading yield surface for overconsolidation (Hashiguchi, 1978, 1989; Asaoka et al., 1997). That is to say, the degree of structure is expressed by means of a superloading surface situated on the outside of the Cam-clay normal-yield surface and similar to it (the center of similarity being the origin $p^{\prime}=q=0$ and the similarity rate being given by $R^{*}$ $\left(0<R^{*} \leq 1\right)$, while the overconsolidation state is expressed by means of a subloading surface situated on the inside of the superloading surface and again similar to it (center of similarity $p^{\prime}=q=0$, similarity rate $R$ $(0<R \leq 1)$; reciprocal $1 / R$ is the overconsolidation ratio). $p^{\prime}$ here is the mean effective stress and $q$ is the shear stress. Using effective stress tensor $\boldsymbol{T}^{\prime}$ (tension: positive),

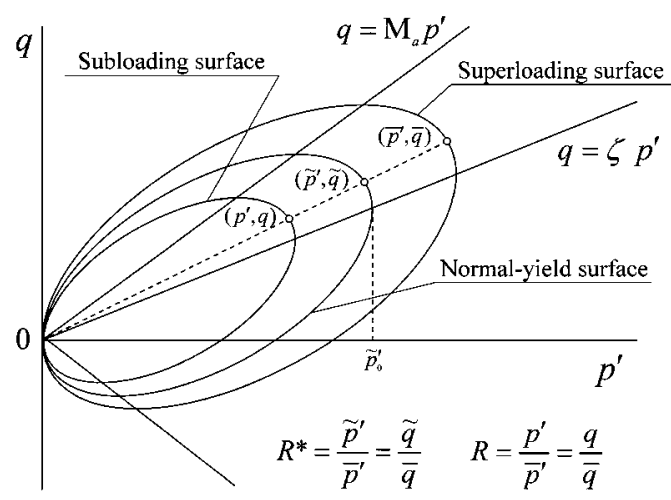

Fig. A1. Three loading surfaces

we can say: $p^{\prime}=-\operatorname{tr} T^{\prime} / 3, q=\sqrt{3 / 2 S \cdot S}$. The closer $R^{*}$ is to 0 the higher the degree of structure, but with the loss of structure that accompanies progressive plastic deformation $R^{*}$ will approach 1 (evolution rule for $R^{*}$ ). Similarly, the closer $R$ is to 0 the more overconsolidated the state of the soil, but as $R$ increases toward 1 with plastic deformation, the state of the soil will also approach normal consolidation (evolution rule for $R$ ). It can thus be assumed that the loss of structure with progressive plastic deformation brings a simultaneous release from overconsolidation (a transition to the normally consolidated state), resulting finally in conditions that match those in the Cam-clay model. The relative positions of the three loading surfaces, assuming conditions of axial symmetry, are as shown in Fig. A1.

If we start from Cam-clay Eq. (A1) below as our base, given that the current effective stress exists on the subloading yield surface, we first need to derive the subloading surface as shown in Eq. (A2), to which various elastoplastic principles such as the associated flow rule and Prager's consistency condition are applied.

The Cam-clay potential:

$$
\begin{array}{r}
\mathrm{MD} \ln \frac{\tilde{p}^{\prime}}{\tilde{p}_{0}^{\prime}}+\mathrm{MD} \ln \frac{\mathrm{M}^{2}+\eta^{* 2}}{\mathrm{M}^{2}}+\int_{0}^{t} J \operatorname{tr} \boldsymbol{D}^{p} d \tau \\
=f\left(\tilde{p}^{\prime}, \eta^{*}\right)+\int_{0}^{t} J \operatorname{tr} \boldsymbol{D}^{p} d \tau=0
\end{array}
$$

The subloading surface:

$$
f\left(\tilde{p}^{\prime}, \eta^{*}\right)+\mathrm{MD} \ln R^{*}-\mathrm{MD} \ln R+\int_{0}^{t} J \operatorname{tr} \boldsymbol{D}^{p} d \tau=0
$$

Here, $\mathrm{D}=(\tilde{\lambda}-\tilde{\kappa}) / \mathrm{M} /\left(1+\mathrm{e}_{0}\right)$ is the dilatancy coefficient, and $\mathrm{M}, \tilde{\lambda}, \tilde{\kappa}$ and $\mathrm{e}_{0}$ are the critical state constant, compression index, swelling index, and initial void ratio. $J=(1+\mathrm{e}) /\left(1+\mathrm{e}_{0}\right)$ (e is the void ratio at time $\left.t=t\right)$. $-\int_{0}^{t} J \operatorname{tr} D^{p} d \tau$ (compression: positive) corresponds to the plastic volumetric strain. $\eta^{*}$, the expression of anisotropy, is obtained using the rotational hardening variable $\boldsymbol{\beta}$, from the calculation $\eta^{*}=\sqrt{3 / 2 \hat{\boldsymbol{\eta}} \cdot \hat{\boldsymbol{\eta}}}, \hat{\boldsymbol{\eta}}=\boldsymbol{\eta}-\boldsymbol{\beta}$, $\boldsymbol{\eta}=\boldsymbol{S} / p^{\prime}, \quad \boldsymbol{S}=\boldsymbol{T}^{\prime}+p^{\prime} \boldsymbol{I} . \quad \boldsymbol{\beta}=\mathbf{0}$ expresses a state of no anisotropy. In the present paper, the evolution rules for $R^{*}, R$ and $\beta$ are given by the following equations.

Evolution rule for $R^{*}$ : 


$$
\dot{R}^{*}=J U^{*}\left\|D^{p}\right\|, \quad U^{*}=\frac{a}{\mathrm{D}} R^{* b}\left(1-R^{*}\right)^{c}
$$

Evolution rule for $R$ :

$$
\dot{R}=J U\left\|D^{p}\right\|, \quad U=-\frac{m}{\mathrm{D}} \ln R
$$

Evolution rule for $\boldsymbol{\beta}$ :

$$
\dot{\boldsymbol{\beta}}=J \frac{b r}{\mathrm{D}} \sqrt{\frac{2}{3}}\left\|\boldsymbol{D}_{s}^{p}\right\|\|\hat{\boldsymbol{\eta}}\|\left(m_{b} \frac{\hat{\boldsymbol{\eta}}}{\|\hat{\boldsymbol{\eta}}\|}-\boldsymbol{\beta}\right)
$$

$\boldsymbol{D}^{p}$ here is the plastic stretching tensor, $\boldsymbol{D}_{s}^{p}$ is the deviator component of $\boldsymbol{D}^{p}$ and \|\| represents its Euclidean norms. $\ddot{\boldsymbol{\beta}}$ in Eq. (A5) is the Green and Nahdhi's (1965) rate of $\boldsymbol{\beta}$. The parameter groups for the evolution rules in Eqs. (A3)-(A5) all consists of constants, and from their respective functions we may call $a, b, c$ the degradation indices of structure, $m$ the degradation index of overconsolidation, $b r$ the rotational hardening index, and $m_{b}$ the rotational hardening limit constant.

The Associated Flow Rule and the Constitutive Equation Associated flow rule:

$$
\boldsymbol{D}^{p}=\lambda \frac{\partial f}{\partial \boldsymbol{T}^{\prime}}, \quad \lambda=\frac{\frac{\partial f}{\partial \boldsymbol{T}^{\prime}} \cdot{\stackrel{\circ}{\boldsymbol{T}^{\prime}}}^{\prime}}{J \frac{\mathrm{MD}}{p^{\prime}\left(\mathrm{M}^{2}+\eta^{* 2}\right)}\left(\mathrm{M}_{\mathrm{s}}^{2}-\eta^{2}\right)}>0
$$

Constitutive equation:

$$
\stackrel{\circ}{\boldsymbol{T}}^{\prime}=\boldsymbol{E D}-\Lambda \boldsymbol{E} \frac{\partial f}{\partial \boldsymbol{T}^{\prime}}
$$

$\boldsymbol{E}$ here is the elastic modulus tensor, $\stackrel{\circ}{\boldsymbol{T}}^{\prime}$ is the Green and Naghdi's (1965) rate of $\boldsymbol{T}^{\prime}$, and $\Lambda$ is the expression of plastic multiplier $\lambda$ in terms to stretching $\boldsymbol{D}$. Further, we can establish the relations:

$$
\begin{aligned}
\mathrm{M}_{s}^{2}= & \mathrm{M}_{a}^{2}+b r \frac{4 \mathrm{M} \eta^{* 2}}{\mathrm{M}^{2}+\eta^{* 2}}\left(m_{b} \eta^{*}-\sqrt{\frac{3}{2}} \hat{\eta} \cdot \boldsymbol{\beta}\right) \\
& -\mathrm{MD}\left(\frac{U^{*}}{R^{*}}-\frac{U}{R}\right) \sqrt{6 \eta^{* 2}+\frac{1}{3}\left(\mathrm{M}_{a}^{2}-\eta^{2}\right)^{2}}
\end{aligned}
$$

and

$$
\mathrm{M}_{a}^{2}=\mathrm{M}^{2}+\zeta^{2}, \quad \zeta=\sqrt{3 / 2}\|\boldsymbol{\beta}\|
$$

The slope $\mathbf{M}_{s}$ of the threshold between hardening and softening $q=\mathrm{M}_{s} p^{\prime}$, obtained under loading conditions $\lambda>0$, varies according to structural degradation, loss of overconsolidation and development or loss of anisotropy, as well as with the current stress ratio. Similarly, the slope $\mathrm{M}_{a}$ of the threshold beween plastic compression and expansion $q=\mathrm{M}_{a} p^{\prime}$ varies in response to the development or loss of anisotropy. For details, the reader is referred to Asaoka et al., 2002.

\section{APPENDIX B: METHOD OF FORMULATING THE INITIAL SOIL CONDITIONS, TAKING ACCOUNT OF SELF-WEIGHT}

The soil is imagined as being homogeneous in the horizontal direction, and as existing in a state $K_{0}$ as determined by the actions of surcharge load $\delta$ and the soil's self-weight. If the depth below the ground surface is $z$, the specific volume $\mathrm{v}_{0}$ is expressed by an equation:

$$
\begin{aligned}
\mathrm{v}_{0} & =\overline{\mathrm{N}}-\tilde{\lambda} \ln \frac{1+2 K_{0}}{3} \sigma_{\imath 0}^{\prime} \\
& =\overline{\mathrm{N}}-\tilde{\lambda} \ln \frac{1+2 K_{0}}{3}\left(\int_{0}^{z} \frac{\rho_{s}-\rho_{w}}{\mathrm{v}_{0}} g d z+\delta\right)
\end{aligned}
$$

where $g$ is the acceleration in gravity force. And, from this Eq. (1) and the assumption that $\boldsymbol{\eta}_{0} \cdot \boldsymbol{\beta}_{0} \geq 0 \overline{\mathrm{N}}$ can then be expressed as

$$
\overline{\mathrm{N}}=\mathrm{N}-(\tilde{\lambda}-\tilde{\kappa}) \ln \frac{R_{0}^{*}}{R_{0}} \frac{\mathrm{M}^{2}+\left(\eta_{0}-\zeta_{0}\right)^{2}}{\mathrm{M}^{2}}
$$

We now consider the case in which $K_{0}, \eta_{0}^{*}, R_{0}^{*}$ and $R_{0}$ maintain constant values in the depth direction. This being so, since the value for $\overline{\mathrm{N}}$ will also stay constant for depth, the derivative for specific volume $\mathrm{v}_{0}$ with respect to depth $z$ can be given by the following Eq. (B3):

$$
\frac{d \mathrm{v}_{0}}{d z}=-\tilde{\lambda} \frac{1+2 K_{0}}{3} \frac{\rho_{s}-\rho_{w}}{\mathrm{v}_{0}} g \exp \frac{\mathrm{v}_{0}-\overline{\mathrm{N}}}{\tilde{\lambda}}
$$

Once the value for $\mathrm{v}_{0}$ at the ground surface is given from Eq. (B1), as in (B4) below, all the successive specific volume distributions can be found using Eq. (B3).

$$
\left.\mathrm{v}_{0}\right|_{z=0}=\overline{\mathrm{N}}-\tilde{\lambda} \ln \frac{1+2 K_{0}}{3} \delta
$$

\section{APPENDIX C: METHOD OF VARYING THE CUTTING ANGLE FOR THE TEST PIECES}

To vary the cutting angle for the test pieces in the study, a manner of sampling was assumed in which materials were first put into an isotropic stress state, and then rigidly rotated. Thinking here only of individual elements, in a soil rendered isotropic and then rigidly rotated in this way any difference in the cutting angle can be regarded as entirely due to rotation $\boldsymbol{\beta}$. This being so, there is no change in mean effective stress $p^{\prime}$ or in $\eta^{*}$, and of course no alteration occurs in the state of the soil.

With these considerations in mind, and thinking in terms of elements, the soil was given as being rigidly rotated in the ways represented by rotation tensor $\boldsymbol{Q}$ in Fig. C1.

$$
\boldsymbol{Q}=\left[\begin{array}{ccc}
\cos \theta & -\sin \theta & 0 \\
\sin \theta & \cos \theta & 0 \\
0 & 0 & 1
\end{array}\right]
$$

Angle $\theta$ represents the cutting angle, and the tensor component expressions all refer to the orthogonal coordinate system attaching to the space shown in the figure. 


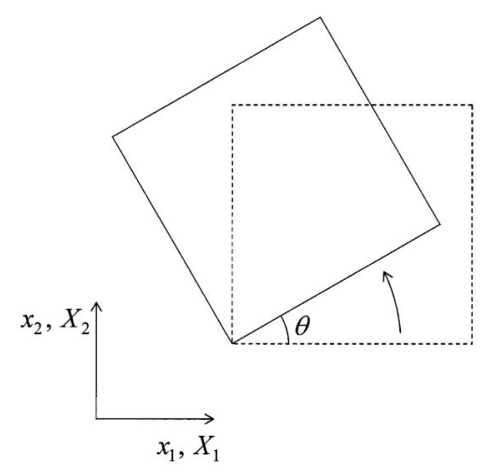

Fig. C1. Uniform rigid rotational field
Imagining also a case in which the deposition surface of the material prior to rigid rotation might lie orthogonally to the $x_{1}$ axis, the components of rotational hardening variable $\boldsymbol{\beta}$ were given as follows.

$$
\boldsymbol{\beta}=\left[\begin{array}{ccc}
2 \zeta / 3 & 0 & 0 \\
0 & -\zeta / 3 & 0 \\
0 & 0 & -\zeta / 3
\end{array}\right]
$$

Rotational hardening variable $\boldsymbol{\beta}^{*}$ after rigid rotation was accordingly calculated from the following equation, and the change in the cutting angle of the test material was expressed.

$$
\boldsymbol{\beta}^{*}=\boldsymbol{Q} \boldsymbol{\beta} \boldsymbol{Q}^{\mathrm{T}}
$$

